روئة تحليلية لمؤشرات الكفاءة الاقتصادية والتسويقية لأهم المحاصيل الغذائية فى مصر

محمد عبد الوهاب أبو نحول ، طلعت حافظ إسماعيل ، جلال عبد الفتاح الصغير، مها عبد المقصود

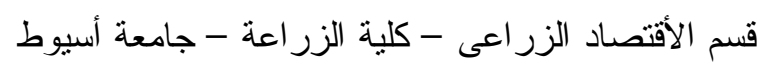

Received on: 3/7/2017

Accepted for publication on:17/7/2017

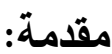

تعتبر در اسة الكفاءة الإقتصادية لإستخدام الموارد الإنتاجية الزر اعية في إنتاج المحاصـيل

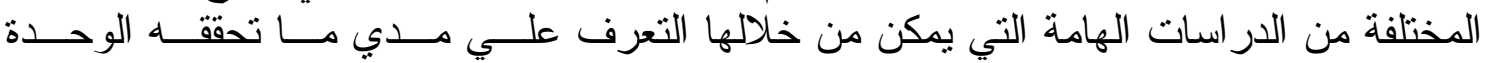

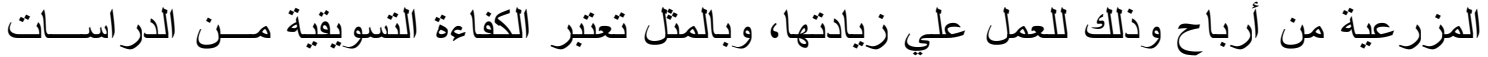

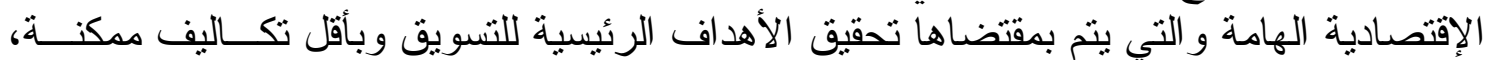

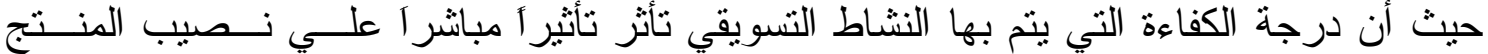

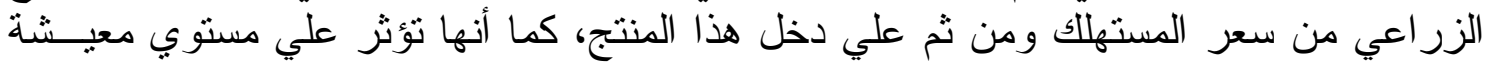

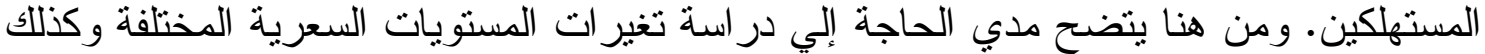

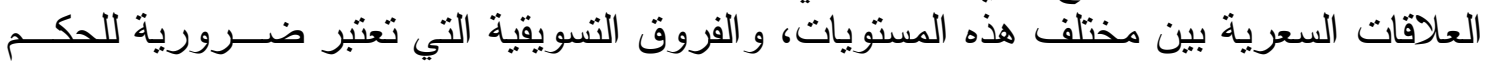

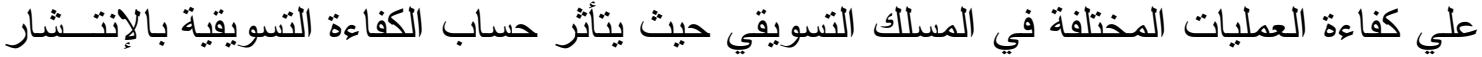

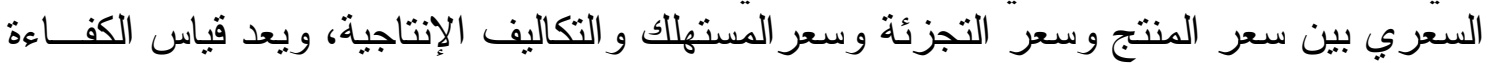

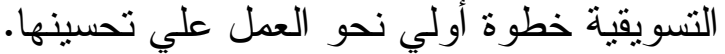

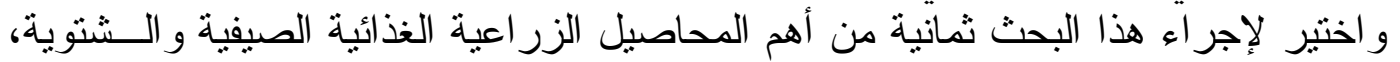

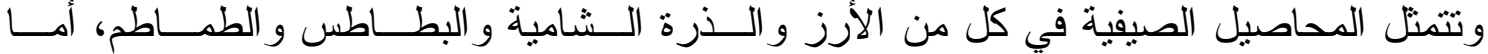

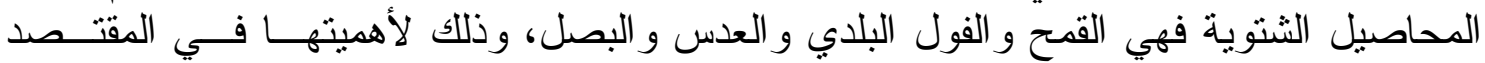

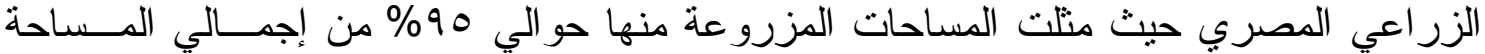

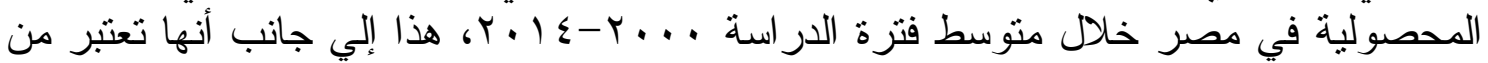

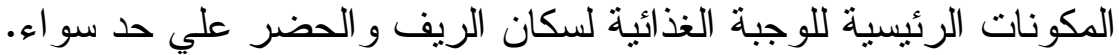

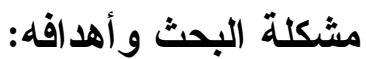

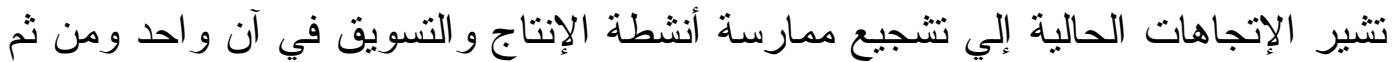

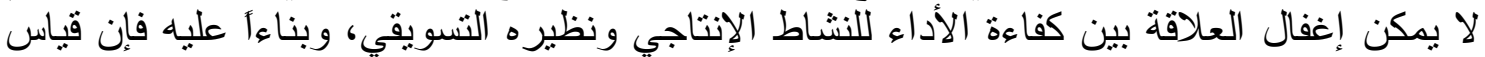

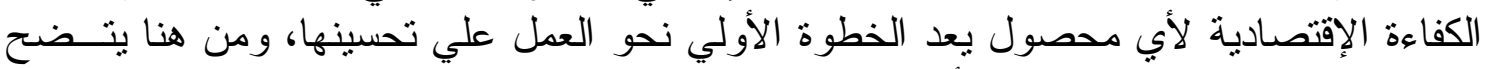

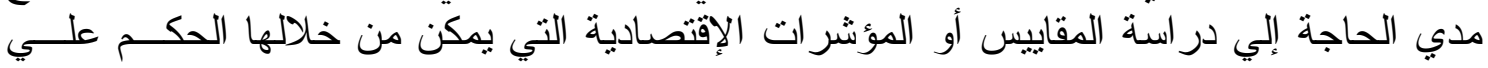

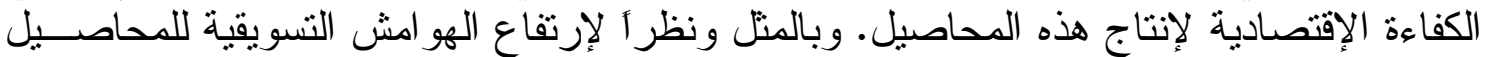

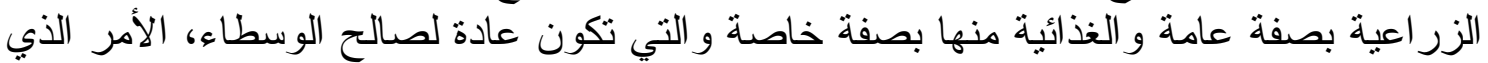

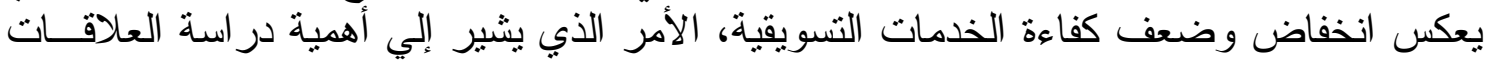

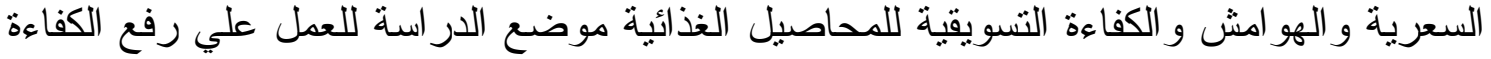
التسويقية ومن ثم تحسين النظام التسويقي. وفي ضوء ذلك فإن الدر اسة تهدف إلى الئي:

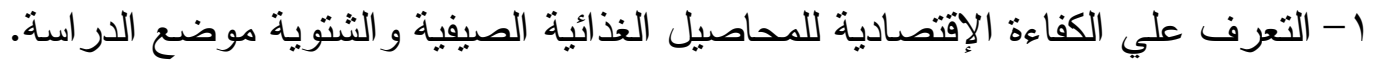

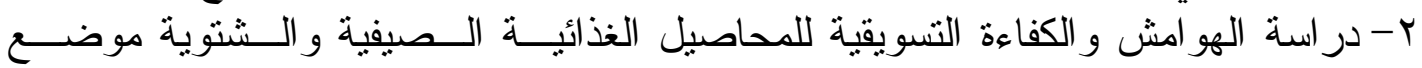

$$
\text { الأسلوب البحثي ومصدادر البيانات: }
$$

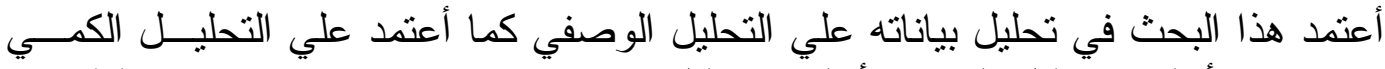

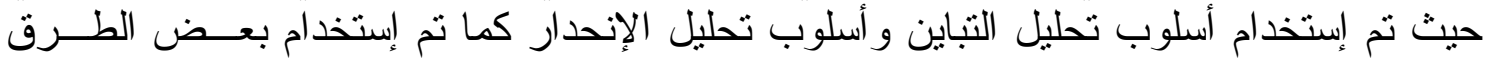




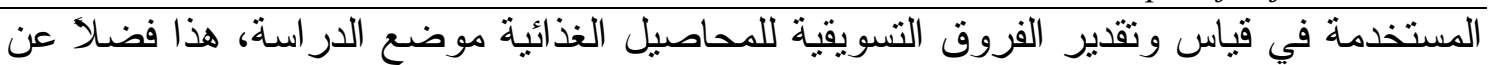

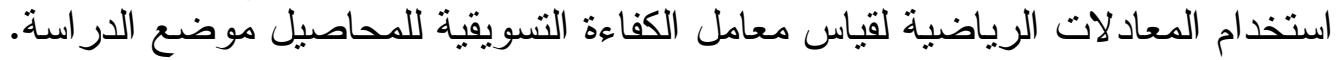

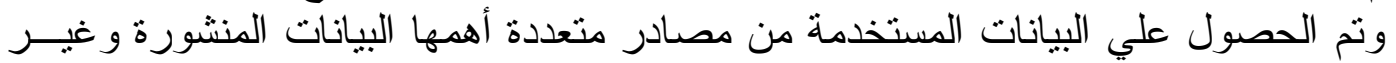

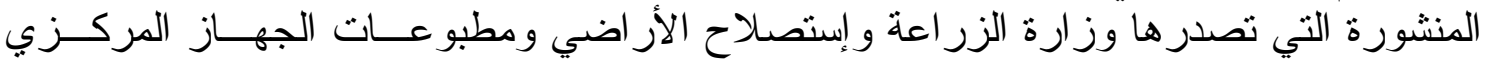

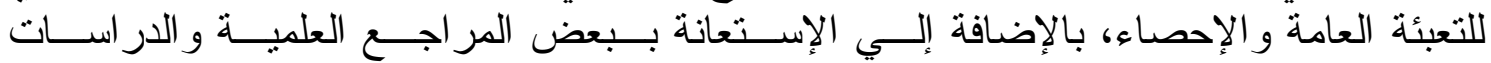

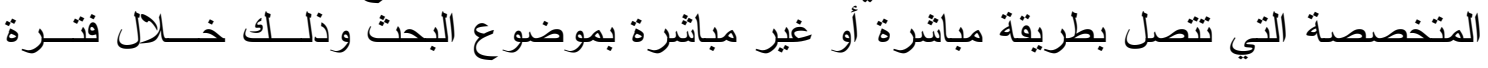

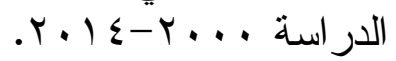

نتائج البحث

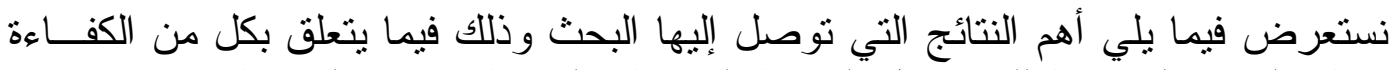

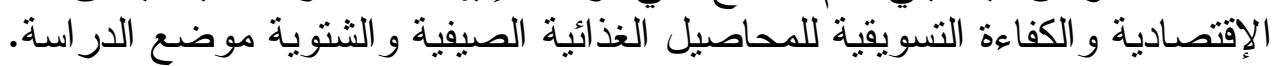

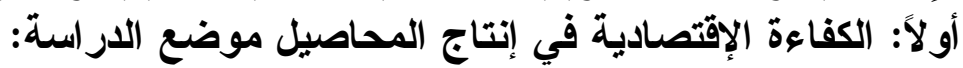

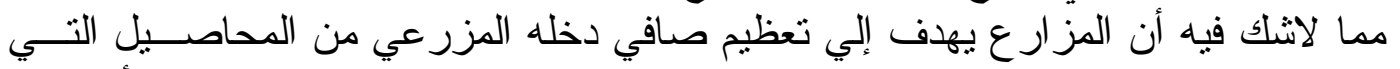

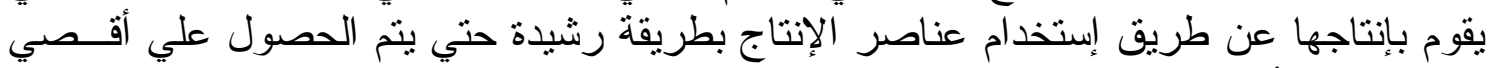

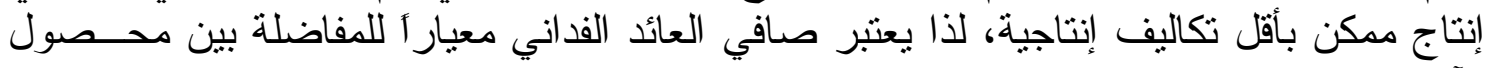

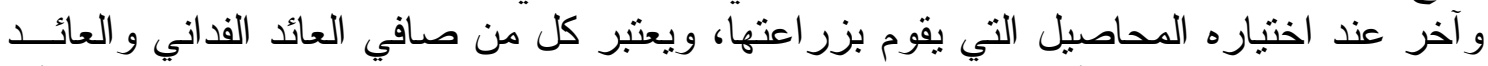

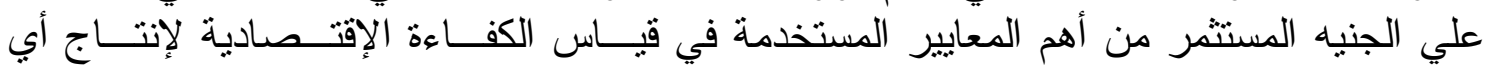
محصول. وللتعرف علي الكفاءة الإقتصادية للمحاصيل الغذائية الصيفية و الثتوية موضـــع الدر اســـة

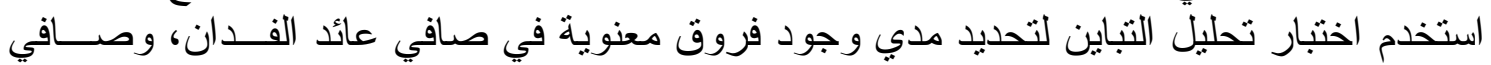

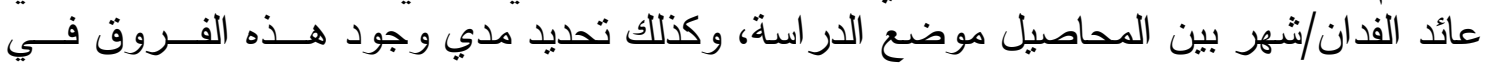

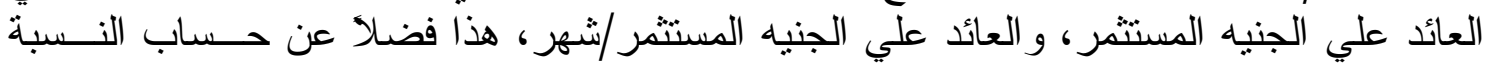
المئوية لنكلفة الوحدة من السعر المزرعي لكل العائ المحاصيل موضع الدر استة. ا 1 أ - للمحاصيل الصيفية: الصئية

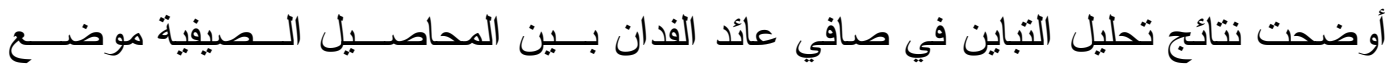

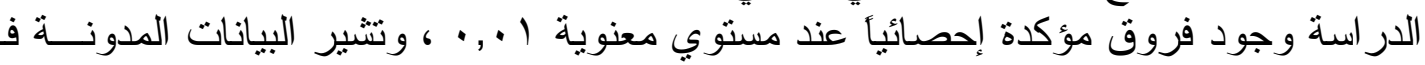

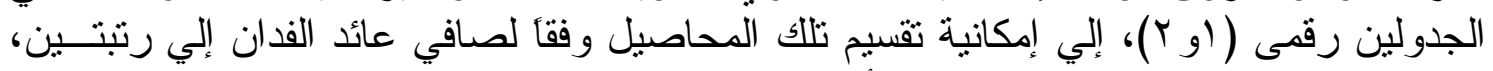

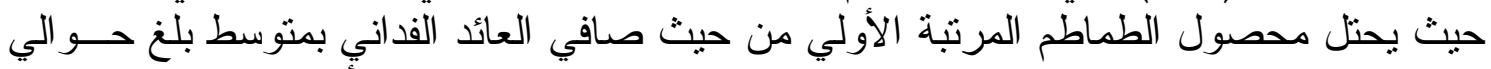

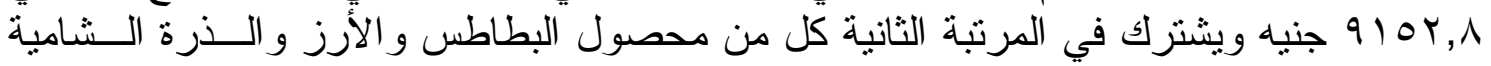

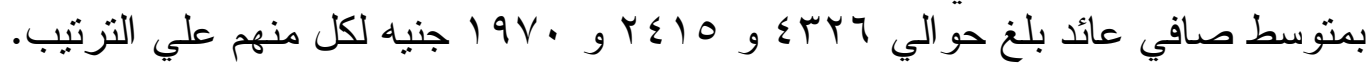


جدول رقم (1): بعض مؤشر ات الكفاءة الإقتصادية للمحاصيل الغذائية الــصيفية والـشتوية موضــع

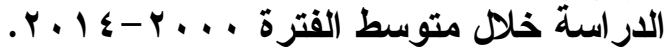

\begin{tabular}{|c|c|c|c|c|c|c|c|c|}
\hline \multicolumn{4}{|c|}{ المحاصيل الثتوية } & \multicolumn{4}{|c|}{ المحاصيل الصيفية } & \multirow{2}{*}{ المحصول البيان } \\
\hline البصل - البصل & 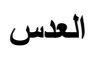 & |الفول البلدى | & القمتح & الطماطم & البطاطس & الذرة الشـامية & الأرز & \\
\hline 7 & 0,0 & 0 & V & 0 & $\varepsilon$ & 0 & 0 & مدة بقاء المحصول فى الأرض بالثهر \\
\hline vorn & rqVर & $\Sigma r \cdot r$ & $O r \leq r$ & 15.09 & 11941 & $\varepsilon \wedge \wedge \uparrow$ & OVYI & الإير اد الكلى للقدان بالجنيه \\
\hline r^०ะ & ro^9 & rATE & rq9. & $r q .7$ & $V 7.0$ & $r 917$ & 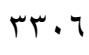 & التكاليف الكلية للقدان بالجنيه \\
\hline$\varepsilon \neg \wedge \varepsilon$ & ITN & $1 \leq 79$ & ror & 9104 & EMr & $19 V$. & $r \leqslant 10$ & صافى العائد للقدان بالجنيه \\
\hline$\vee \wedge l$ & Y01 & rqะ & דיז & $|\wedge|$ & $1 \cdot \lambda r$ & एq & $\varepsilon \wedge \mu$ & صافى العائد للفدان بالجنيه / شهر \\
\hline $1, \varepsilon 1$ & $\cdot, \varepsilon \varepsilon$ & $\cdot, 01$ & $\cdot, \wedge)$ & $r, 10$ & (ז & $\cdot, 7 V$ & $\cdot, V Y$ & عائد الجنيه المستثمر \\
\hline$\cdot, r \varepsilon$ & $\cdot, \cdot \Lambda$ & $\cdot, 1$ & $\cdot, 14$ & $\cdot, \Sigma \Gamma$ & $\cdot, 17$ & $\cdot, 1 T$ & $\cdot, 1 \leqslant$ & عائد الجنيه المستثثر / شهر \\
\hline$r \mid \varepsilon$ & oro & ret & 170 & $r \cdot 1$ & $7 \leq \Lambda$ & Tra & $\wedge 1$ & تكلفة الوحده بالجنيه \\
\hline $0 \leq Y$ & $V \leq r$ & $\leq \leqslant 0$ & roo & $\wedge 1$. & $1 \ldots 1$ & $19 r$ & $|r v|$ & السعر المزرعى بالجنيه \\
\hline$\varepsilon$. & VY & VY & 70 & ro & 70 & $7 \leq$ & 7. & \% تكلفة الوحدة من السعر المزرعى \\
\hline
\end{tabular}

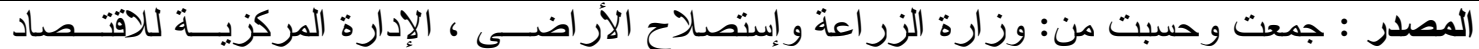
الزر اعي، نشرة الإحصاءات الزر اعية، أعداد متفرقة.

جدول رقم (ץ): نتائج إختبار أقلّ فرق معنوي لترتيب المحاصيل الصيفية والثتوية موضع الدار اســة

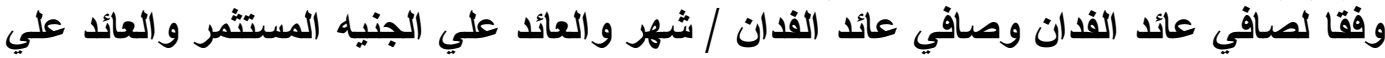

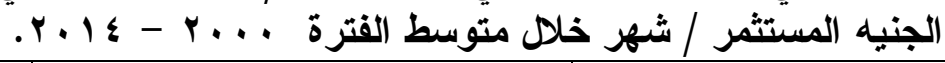

\begin{tabular}{|c|c|c|c|c|c|c|c|c|}
\hline \multicolumn{4}{|c|}{ المحاصيل الشتوية } & \multicolumn{4}{|c|}{ المحاصيل الصيفية } & \multirow[b]{2}{*}{ الظاهـــرة } \\
\hline 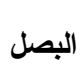 & 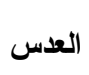 & الفول البلاي & القمح & 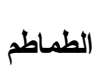 & 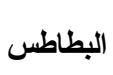 & | الذرة الشامية & 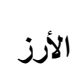 & \\
\hline$\leqslant\rceil \wedge \leqslant$ & ITN & $1 \leqslant 7 \wedge$ & rror & 9104 & $\varepsilon r M q$ & 198. & $r \leqslant 10$ & متوسط صافي عائد الفدان بالجنيه \\
\hline 1 & r & r & r & 1 & $r$ & $r$ & $r$ & الترتيب \\
\hline VA & rol & rqะ & rrt & $|\wedge|$ & $1 \cdot \lambda r$ & rqs & $\varepsilon \wedge r$ & متوسط صافي عائد الفدان بالجنيه / شهر \\
\hline 1 & $r$ & r & r & 1 & r & $r$ & r & الترتيب \\
\hline $1, \varepsilon 1$ & $\cdot, \leqslant \varepsilon$ & $\cdot, 01$ & $\cdot, \wedge)$ & $r, 10$ & 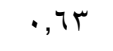 & $\cdot, 7 \mathrm{~V}$ & $\cdot, V Y$ & العائد علي الجنيه المستثمر \\
\hline 1 & r & r & r & 1 & r & r & r & الترتيب \\
\hline$\cdot, r \leq$ & $\cdot, \cdot \wedge$ & $\cdot, 1$ & $\cdot, 1 T$ & $\cdot, \varepsilon \Gamma$ & $\cdot, 17$ & $\cdot, 1 T$ & $\cdot, 1 \leq$ & العائد علي الجنيه المستثر / شهر \\
\hline 1 & $r$ & r & $r$ & 1 & $r$ & $r$ & $r$ & الترتيب \\
\hline
\end{tabular}

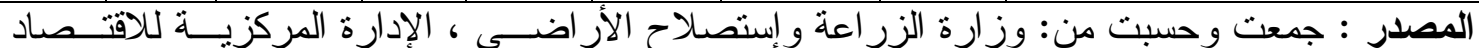
الزر اعي، نشرة الإحصاءات الزر اعية، أعداد منقرقة.

وبتقدير نماذج الإتجاه الزمني العام لتطور صافي العائد الفداني للمحاصيل الصيفية موضع

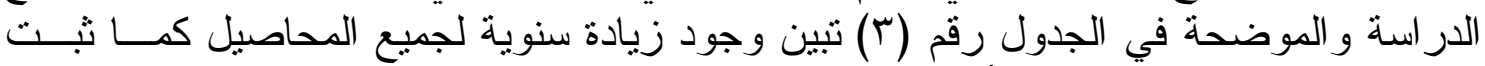

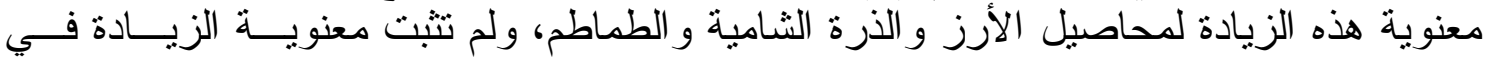
صافي العائد الفداني لمحصول الزدة البطاطس. 


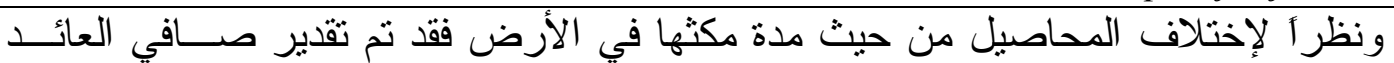

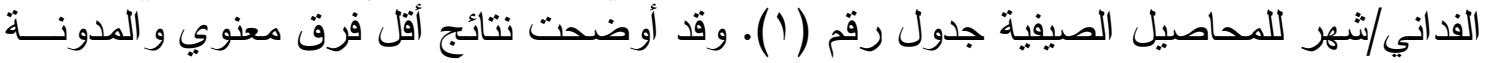

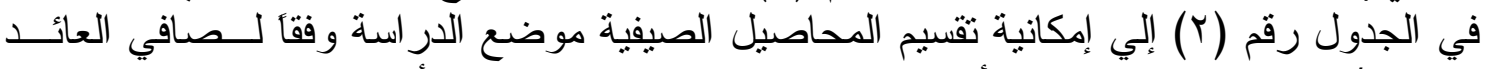

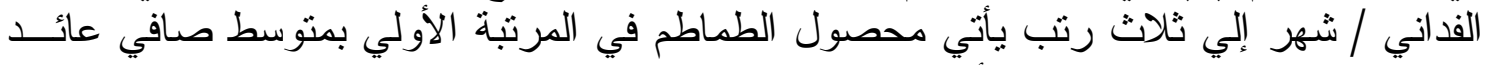

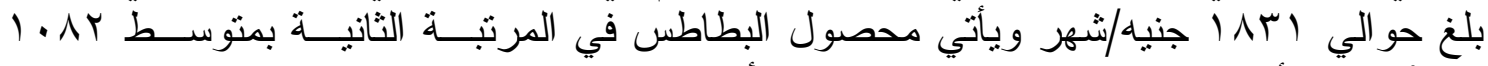

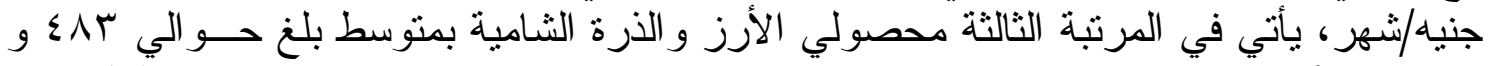

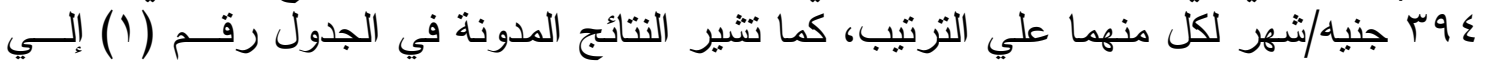

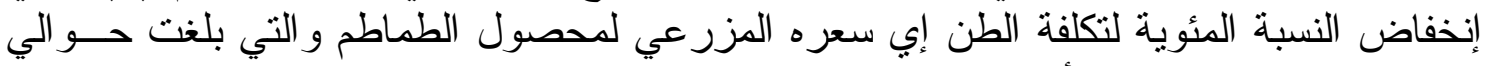

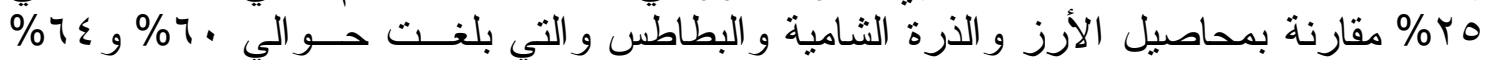

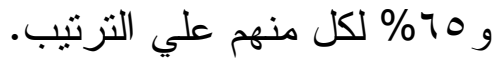
وبتقدير نماذج الإتجاه الزمني العام لصافي العائد الفداني جنيه/شهر للمحاصـــيل الــــيفية

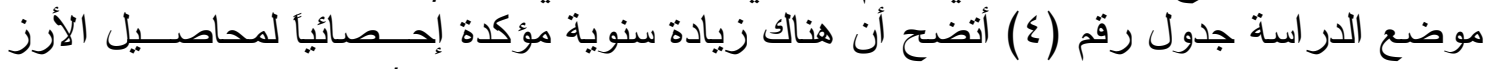

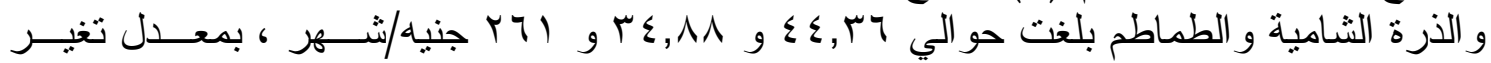

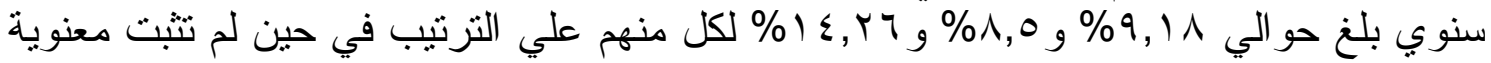
الزيادة السنوية للفحصول جي البطاطس.

\section{ب - للمحاصيل الشتوية:}

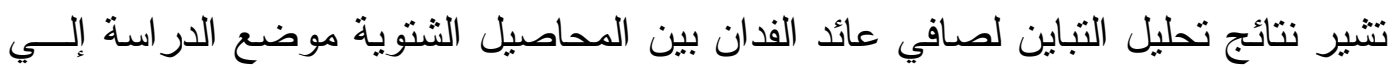

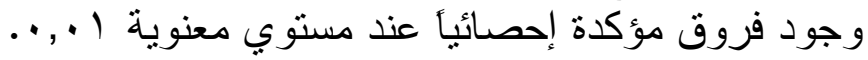

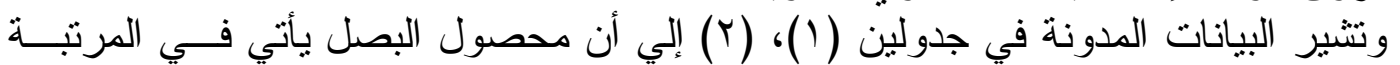

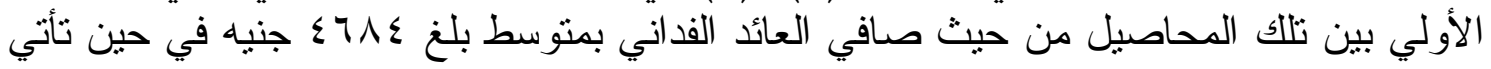

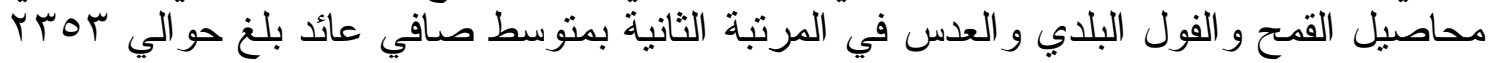

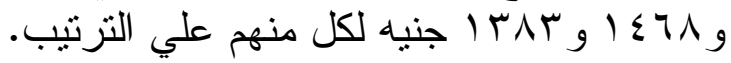

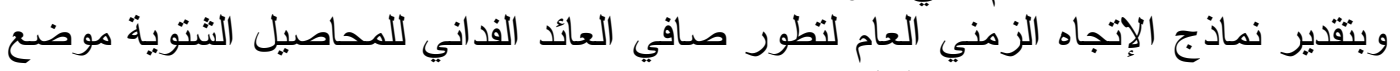

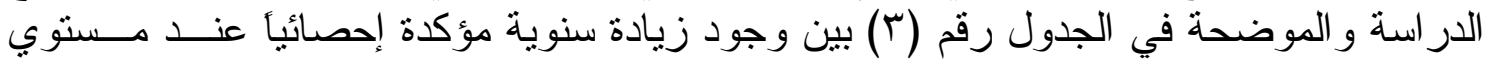

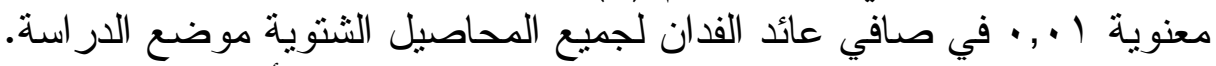

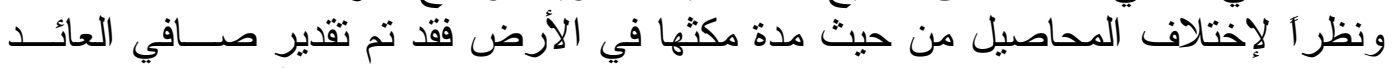

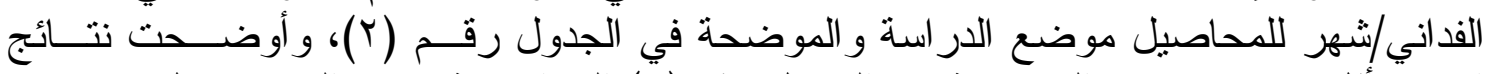

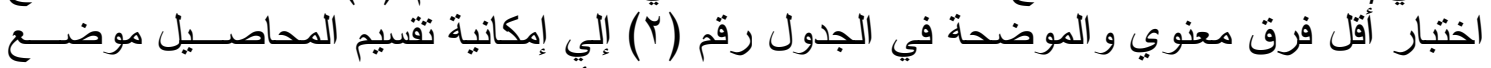

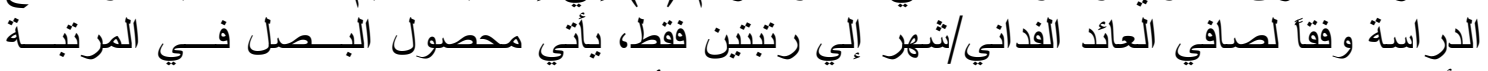

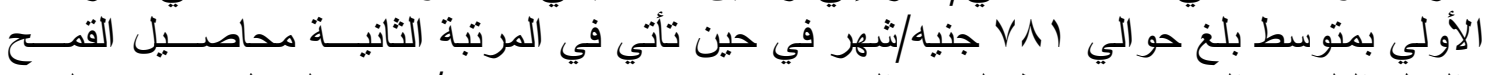

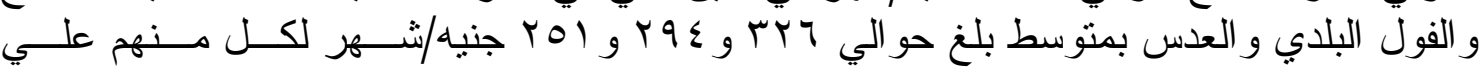
الترنيب. 
جدول رقم (ץ): نماذج الاتجاه الزمنى العام لصافى عائد الفدان بالجنيه للمحاصيل الغذائية الــصيفية

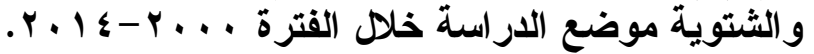

\begin{tabular}{|c|c|c|c|c|c|c|c|}
\hline $\begin{array}{c}\text { معدل التغير } \\
\text { \% }\end{array}$ & المتوسط & مقدار التغير & المحسوبة & נر & المعادلة & \multicolumn{2}{|c|}{ المحاصيل } \\
\hline 9,11 & $r \leqslant 10,1 \mathrm{~V}$ & YYI, Vq & $* * \vee \neg$, OV & $\cdot, \wedge 00$ & $\begin{array}{l}\Delta س Y Y l, \vee q+Y \varepsilon \cdot, \vee q=\wedge \\
* *(\wedge, \vee \theta)\end{array}$ & الأرز & \multirow{4}{*}{ الصيفية } \\
\hline $19,0 r$ & $\wedge q ., q$. & $\mid V \varepsilon, \varepsilon$. & $* * £ \backslash, \wedge \wedge$ & $\cdot, \vee \vee T r$ & 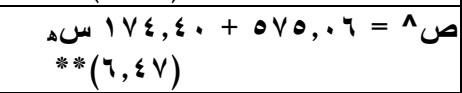 & الشامية & \\
\hline- & - & - & $1, \wedge 11$ & $\cdot, I Y r$ & 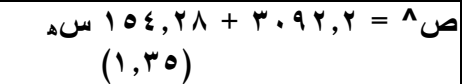 & البطاطس & \\
\hline $1 \leq, Y 7$ & 91 or, $\wedge 9$ & $M \cdot \varepsilon, \wedge$ & $* 00, \vee 0$ & $\cdot, \wedge \backslash 1$ & 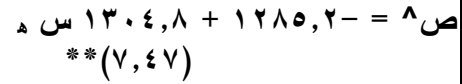 & الطماطم & \\
\hline $1 \cdot, \cdot \varepsilon$ & rrov, $A$ & rOV,VT & $* * \varepsilon \cdot, \leq \leq$ & $\cdot, \mathrm{V} O \mathrm{~V}$ & 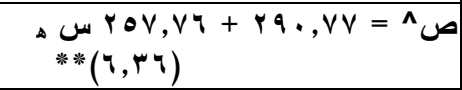 & القـح & \multirow{4}{*}{ الثتوية } \\
\hline $1 \cdot, 01$ & $10 \ldots, r 9$ & $101,9 \mathrm{~V}$ & **or,or & $\cdot, V Y)$ & $\begin{array}{l}\text { ص } 101,9 \vee+r \Delta Y, V V=\wedge \\
* *(0, V 9)\end{array}$ & الفول البلاى & \\
\hline $1 \wedge, r q$ & $1 r \wedge r, \wedge q$ & ros,r & $* * \Delta, T Y$ & $\cdot, \wedge \backslash \wedge$ & 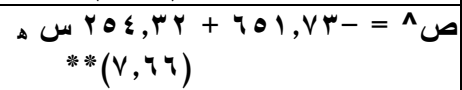 & العدس & \\
\hline$r), \wedge \varepsilon$ & • & $\wedge \cdot 1, \wedge$ & $* * r \vee \neg, \cdot 1$ & $\cdot, 900$ & 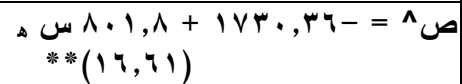 & البصل & \\
\hline
\end{tabular}

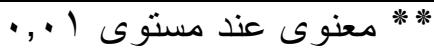

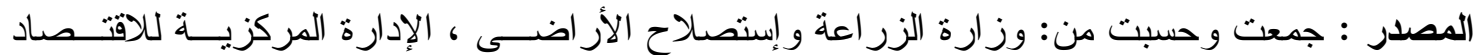

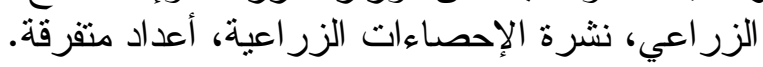

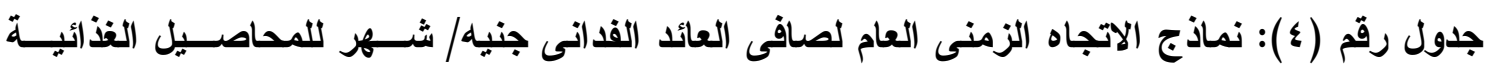

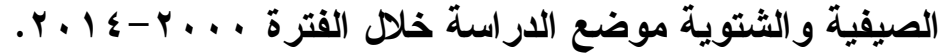

\begin{tabular}{|c|c|c|c|c|c|c|c|}
\hline التغير معدل & المتوسط & مقدار & المحسوبة & ru & المعادلة & \multicolumn{2}{|c|}{ المحاصيل } \\
\hline 9,11 & $\varepsilon \wedge r, \cdot r$ & $\varepsilon \varepsilon, \Gamma \tau$ & $* * \vee \neg, O \vee$ & $\cdot, 100$ & 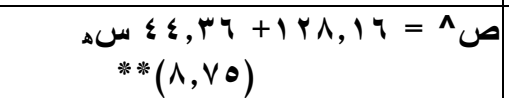 & الأرز & \multirow{4}{*}{ الصيفية } \\
\hline$\wedge, \wedge \diamond$ & rqะ, . 0 & $\Gamma \varepsilon, \wedge \wedge$ & $* * \varepsilon 1, \wedge \wedge$ & מד, • & 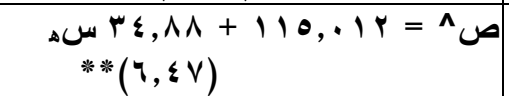 & الثامية الذرة & \\
\hline- & - & - & $1, \wedge 11$ & •, ITr & 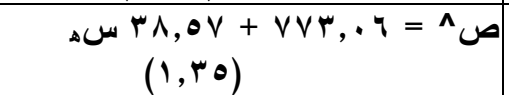 & البطاطس & \\
\hline $1 \leq, Y_{T}$ & $1 \wedge r \cdot, 07$ & YYI, . & $* * 0, \vee \vee 0$ & $\cdot, \wedge 11$ & 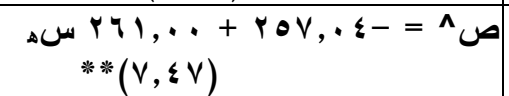 & الطماطد & \\
\hline $1 ., 90$ & זו, צr" & $r Y, \wedge r$ & $* * \varepsilon,, \leq \varepsilon$ & $\cdot, V O V$ & $\begin{array}{l}\Delta \sim r, \wedge r+\varepsilon 1,0 \leqslant=\wedge \\
* *(\uparrow, r q)\end{array}$ & القمح & \multirow{4}{*}{ الشتوية } \\
\hline סז, 1 & $r q r, v$. & $r \cdot, r q$ & r, & $\cdot, V Y I$ & $\begin{array}{l}\Delta س w_{*} r, r q+0 \cdot, 0 q=\Lambda \\
* *(0, \vee q)\end{array}$ & البلدى الفول & \\
\hline $1 \wedge, 19$ & rol, & $\varepsilon \neg, Y \leqslant$ & $* * \Delta \wedge, \nearrow Y$ & $\cdot, \lambda \backslash \wedge$ & 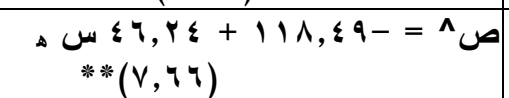 & العدس & \\
\hline$I V, I Y$ & $V \wedge \cdot, T \vee$ & זד,דזו & $* * Y \vee \neg, \cdot 1$ & $\cdot, 900$ & 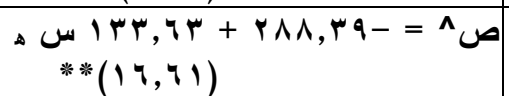 & البصل & \\
\hline
\end{tabular}

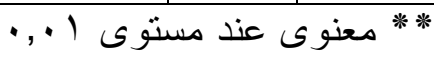

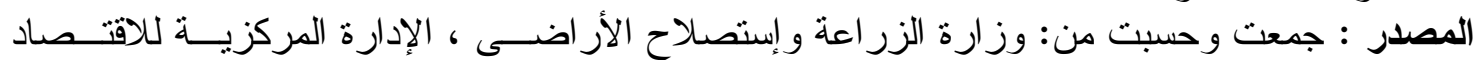
الزر اعي، نشرة الإحصاءات الزر اعية، أعداد متفرقة. 
كما تشير النتائج المدونة في الجدول رقم (1) (1) إلي انخفاض النسبة المئوية لتكلفة الطن من

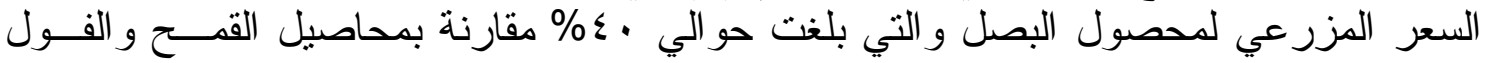

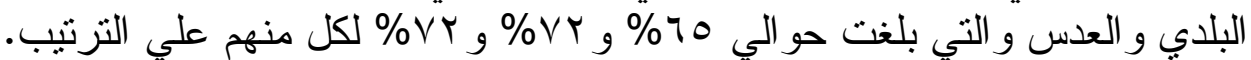

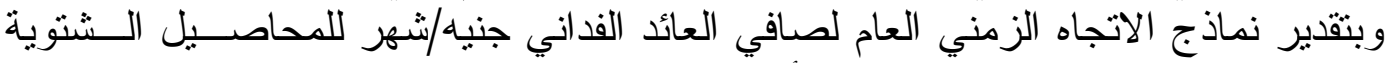

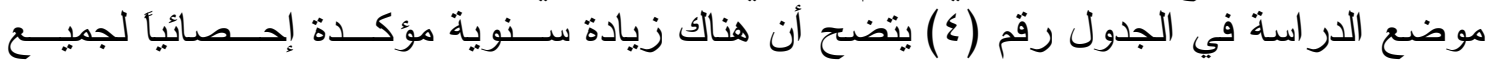

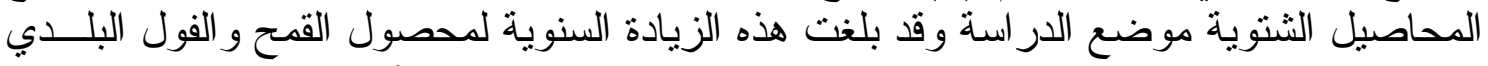

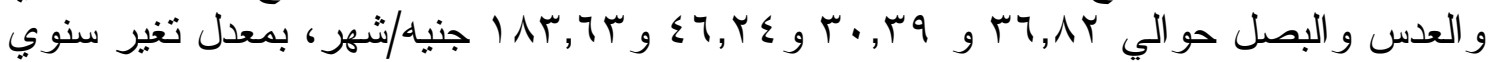

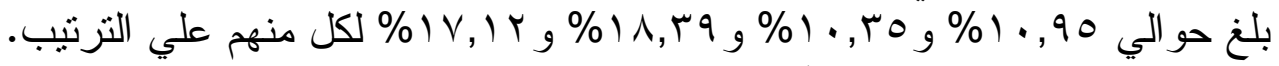

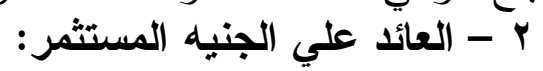

\section{أ - للمحاصيل الصيفية:}

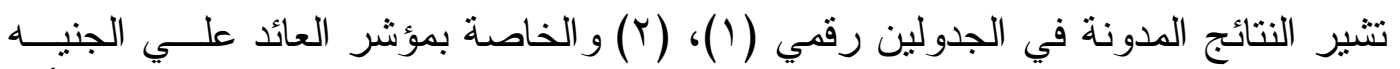

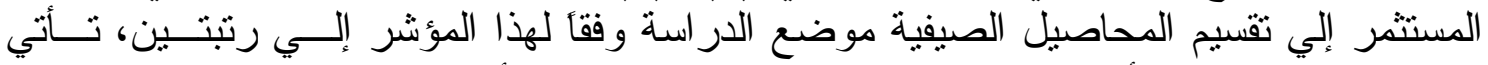

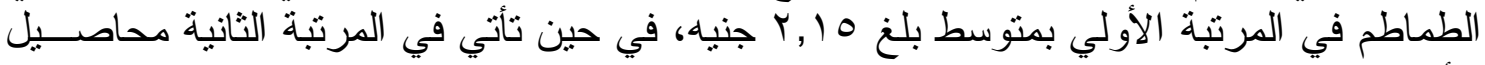

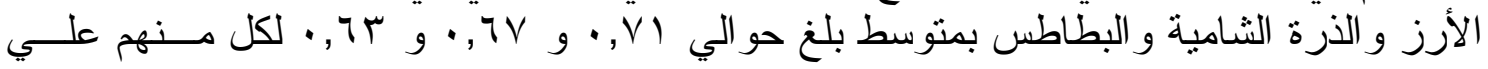
الترتيب.

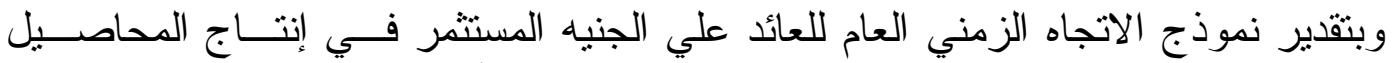

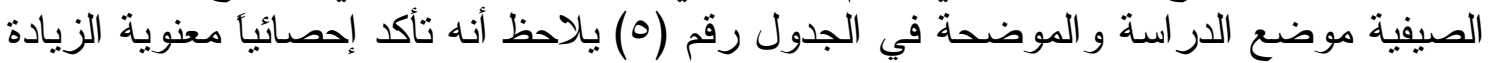

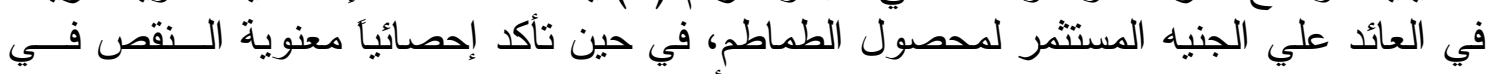

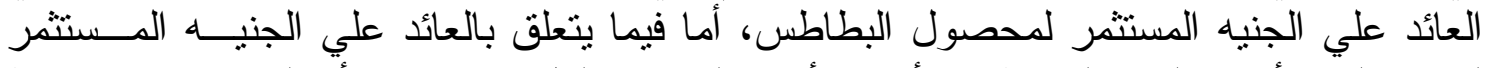

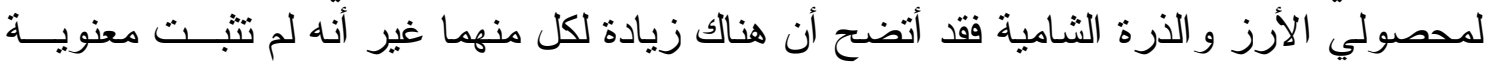
هذه الزيادة إحصائياً.

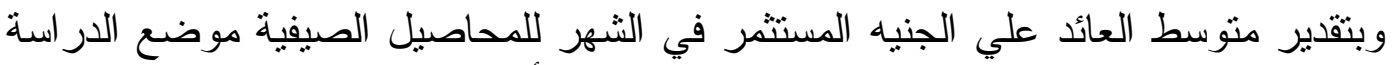

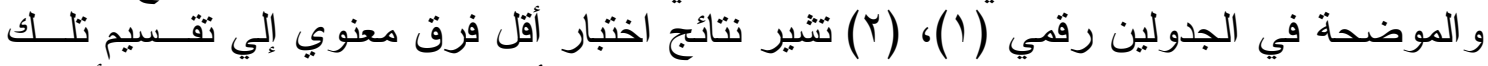

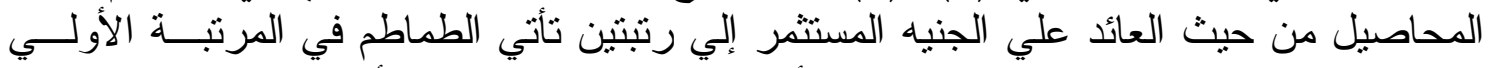

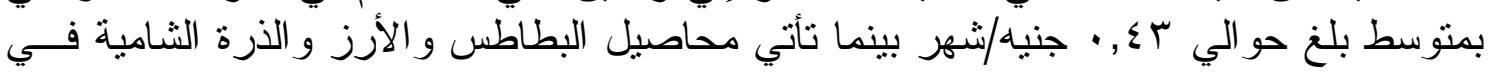

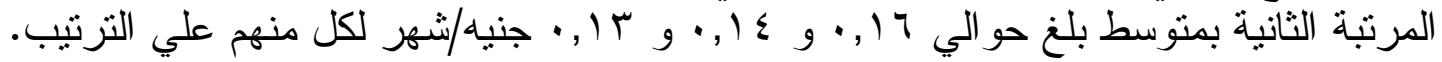

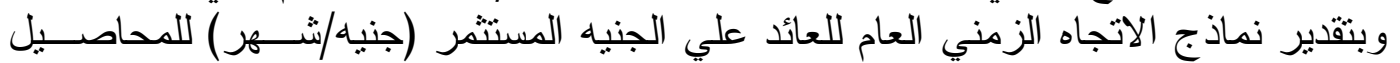

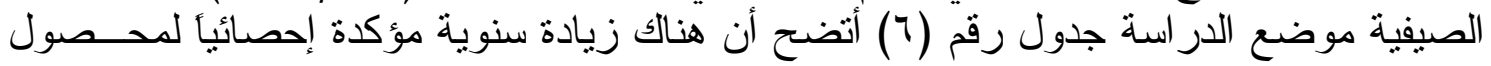

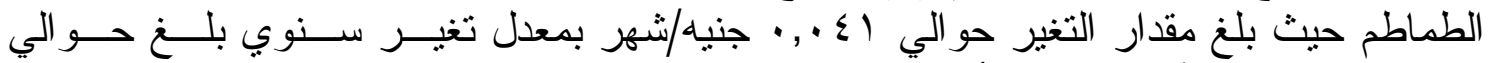

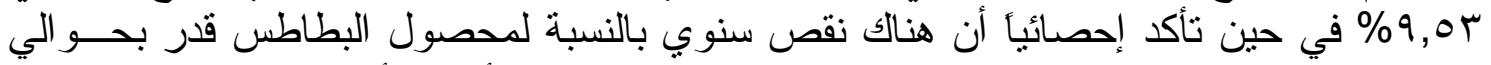

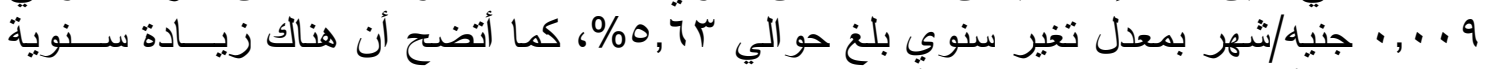

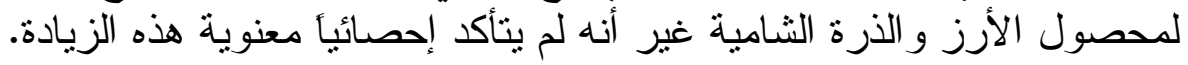


جدول رقم (0): نماذج الاتجاه الزمنى العام للعائد على الجنيه المستثمر فى إنتاج المحاصيل الغذائيــة

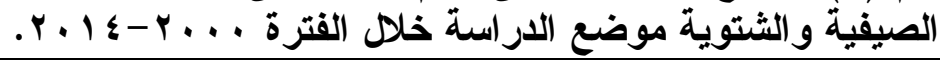

\begin{tabular}{|c|c|c|c|c|c|c|c|}
\hline التغير \%عل \% & المتوسط & مقدار & ف المحســوبة & r & المعادلة & بــــ & المحاصي \\
\hline- & - & - & $\cdot, \wedge 9 \vee$ &., .70 & 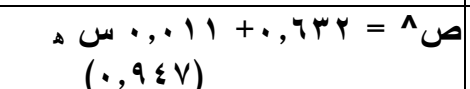 & الأرز & \multirow{4}{*}{ الصيفية } \\
\hline- & - & - & $\cdot, 1 \cdot r$ & $\cdot, \cdots \wedge$ & 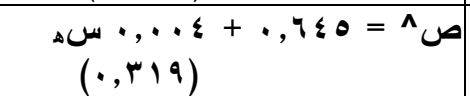 & الثامية & \\
\hline 7, ro & זדו, • & $\cdot, \cdot r V-$ & $* V, Y T$ & $\cdot$, rov & ص ص & 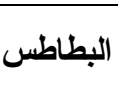 & \\
\hline 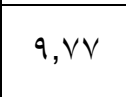 & $r, 10$ & $\cdot, Y \cdot V$ & $* * 41,99$ & $\cdot, V \backslash 1$ & ه & الطماطم & \\
\hline- & - & - & $1, \cdot 9$ & $\cdot, \cdot V V$ & 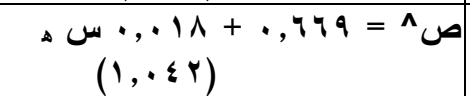 & القمتح & \multirow{4}{*}{ الثتوية } \\
\hline- & - & - & $\cdot, r q$ & $\cdot, \cdot R T$ & 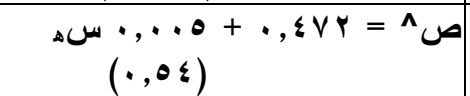 & البلدي & \\
\hline $1 T, 7 \varepsilon$ & $\cdot, \varepsilon \varepsilon$ & זT •,. & $* * r v, 09$ & $\cdot, V \leqslant r$ & 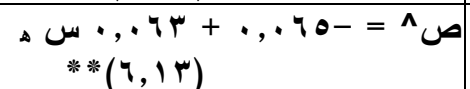 & العلس & \\
\hline$r \cdot, \varepsilon r$ & • & $\cdot, r$. & $* * \mid r \wedge, r_{0}$ & $\cdot, 9 \cdot 1$ & 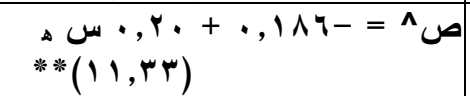 & البصل & \\
\hline
\end{tabular}

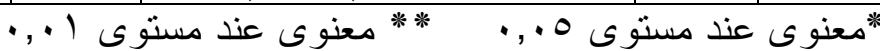

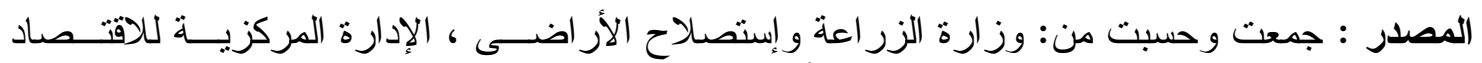
الزر اعي، نشرة الإحصاءات الزر اعية، أعداد متفرقة.

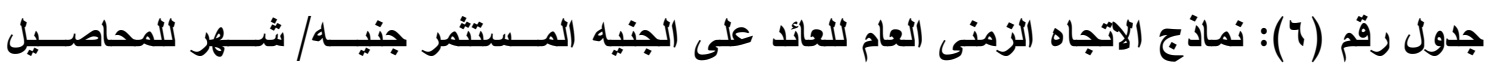

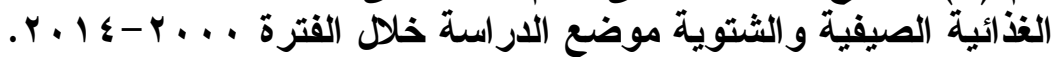

\begin{tabular}{|c|c|c|c|c|c|c|c|}
\hline $\begin{array}{c}\text { معدل التغير } \\
\text { \% }\end{array}$ & |المتوسط & 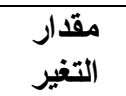 & المحسوبة & נر & المعادلة & \multicolumn{2}{|c|}{ المحاصيــلـل } \\
\hline-- & -- & -- & $\cdot, \wedge 9 \vee$ & $\cdot, .70$ & $\begin{array}{l}\Delta س \cdot, \cdot, r+\cdot, \mid r q=\wedge \\
(\cdot, q \leq V)\end{array}$ & الأزز & \\
\hline-- & -- & -- & $\cdot, 1 \cdot r$ & $\cdot, \cdots \wedge$ & 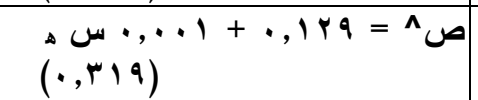 & المامية & ف \\
\hline $0,7 r-$ & $\cdot, 17$ & $-\cdot, \cdots q$ & $* V, r r$ & $\cdot, r \circ V$ & 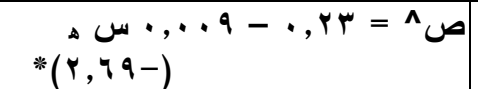 & البطاطس & تصئ \\
\hline 9,04 & $\cdot, \varepsilon r$ & $\cdot, \cdot, \leqslant 1$ & $* * r_{1}, 99$ & $\cdot, \vee \backslash \backslash 1$ & 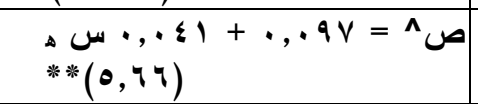 & الطماطم & \\
\hline-- & -- & -- & $1, \cdot 10$ & $\cdot, \cdot v V$ & 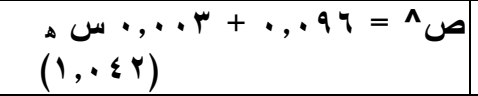 & القمح & \\
\hline-- & -- & -- & $\cdot, Y 91$ & $\cdot, \cdot Y Y$ & 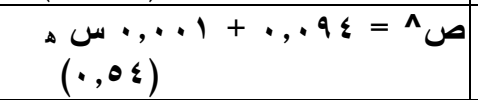 & الفول البلاى & تה \\
\hline $1 T, v_{0}$ & $\cdot, \cdot \wedge$ & $\cdot, .11$ & $* * r \vee, 09$ & $\cdot, v \leqslant r$ & 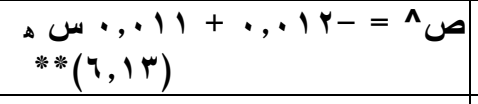 & العلس & \\
\hline $1 T, v_{0}$ & $\cdot, r \varepsilon$ & 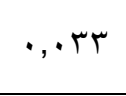 & $* * \mid r \wedge, r_{0}$ & $\cdot, 9 \cdot 1$ & 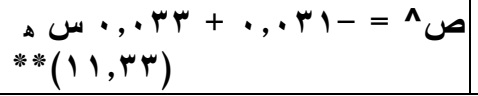 & البصل & \\
\hline
\end{tabular}

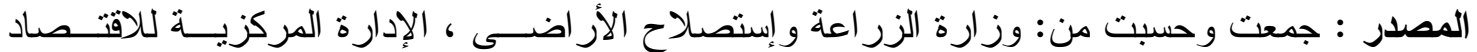
الزر اعي، نشرة الإحصاءات الزر اعية، أعداد متقرقة. 


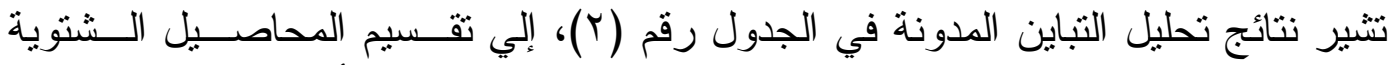

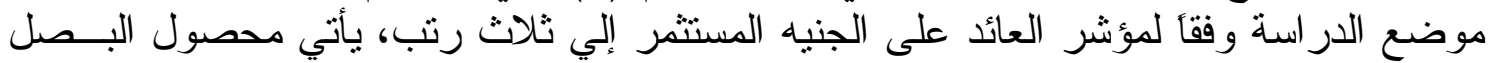

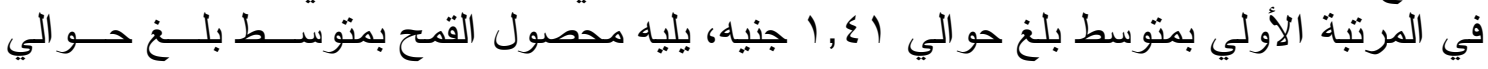

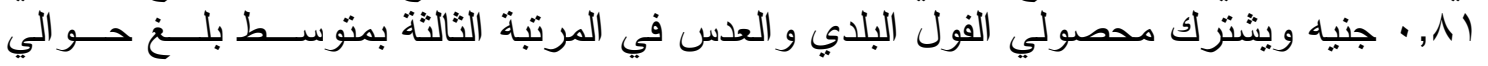
1

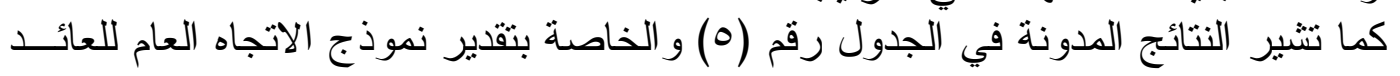

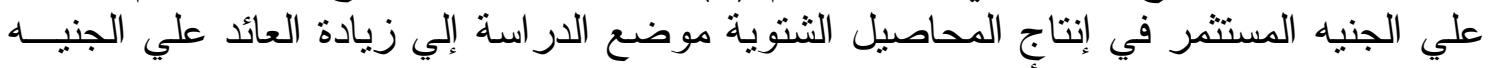

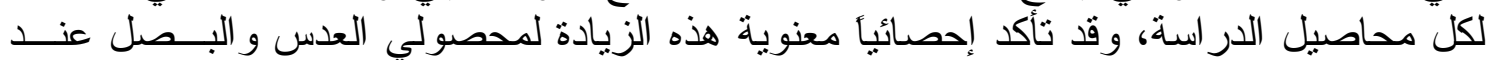

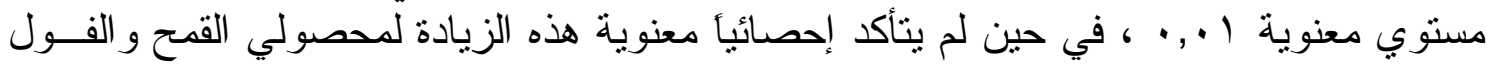
البلدي.

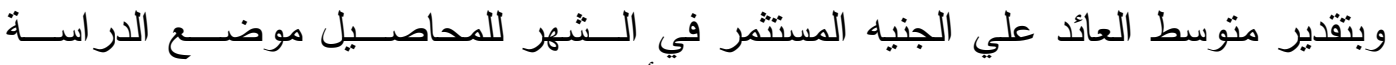

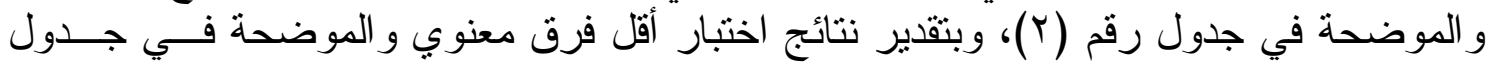

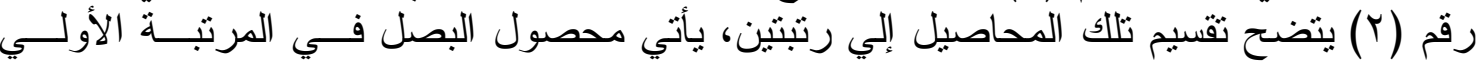

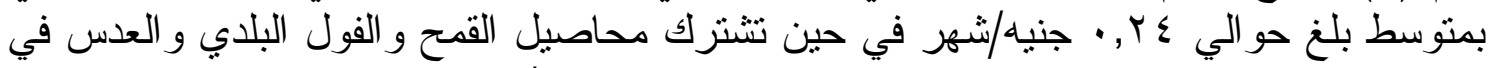

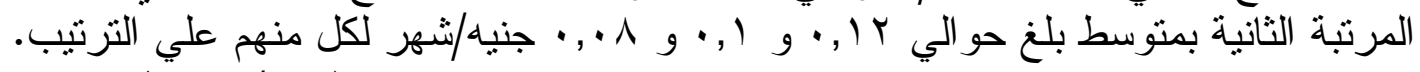

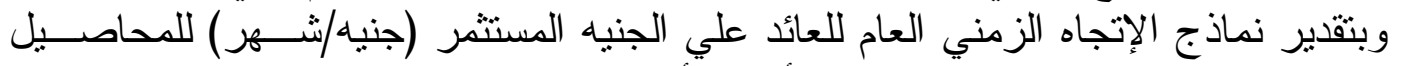

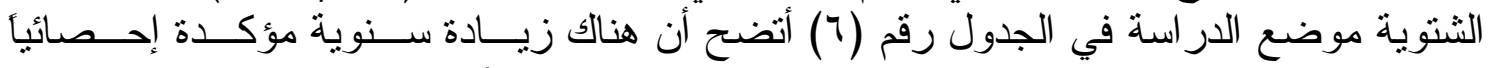

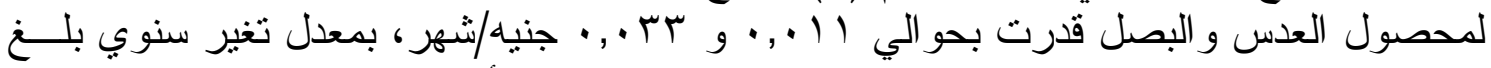

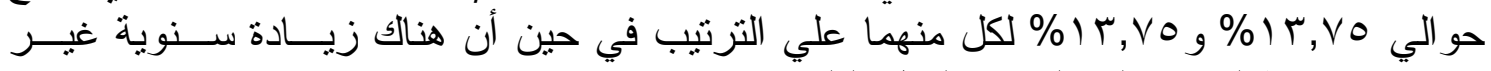

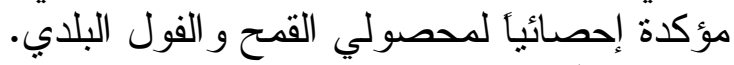

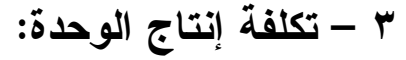

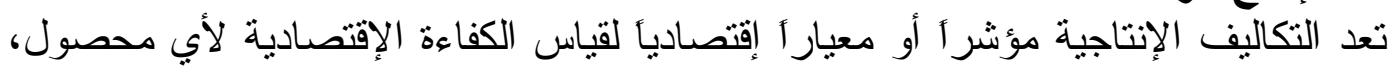

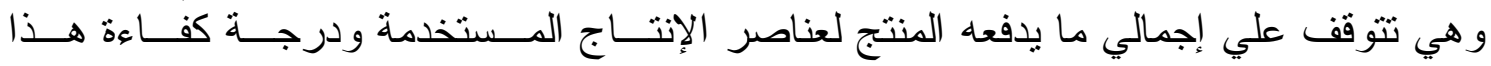

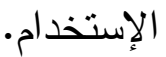

\section{| أ - للمحاصيل الصيفية:}

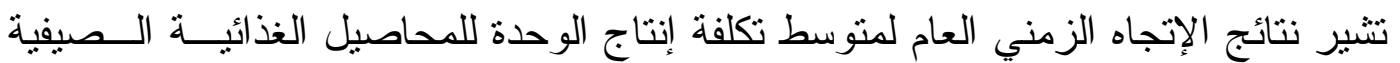

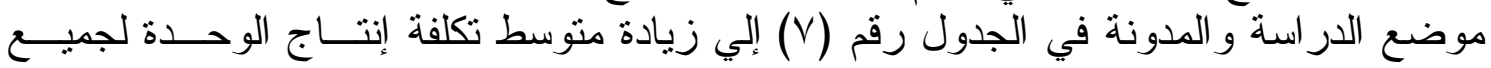

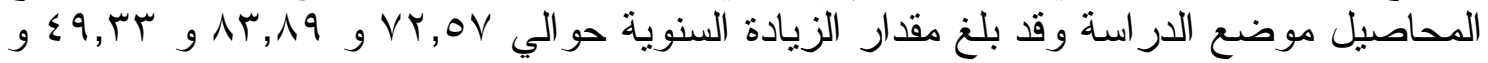

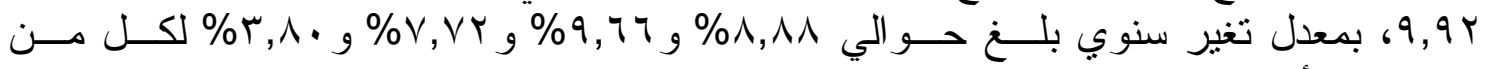

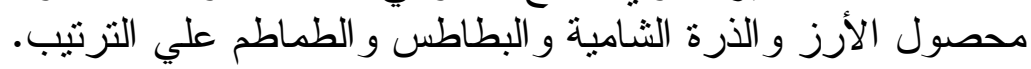

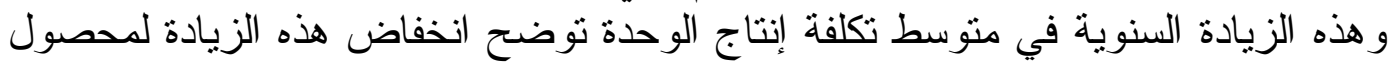

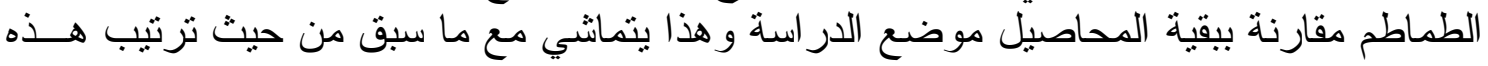
المحاصيل وفقاً لصافي عائد الفدان و العائد علي الجنيه المستثر . 
جدول رقم (V): نماذج الاتجاه الزمنى العام لمتوسط تكلفة إنتاج الوحدة بالجنيه للمحاصـيل الغذائيسـة

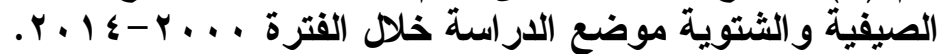

\begin{tabular}{|c|c|c|c|c|c|c|c|}
\hline $\begin{array}{l}\text { معدل التغير \% } \\
\text { \% }\end{array}$ & المتوسط & 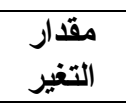 & ت المحسوبة & ij & المعادلة & \multicolumn{2}{|c|}{ المحاصيـلـل } \\
\hline$\wedge, \wedge \Lambda$ & $\wedge \backslash \vee, \varepsilon \wedge$ & $V Y, O V$ & **Tו & $\cdot, 901$ & $\begin{array}{l}\Delta \omega_{* *} V r, \diamond V+r r q, \wedge q=\wedge \\
*(I V, \wedge)\end{array}$ & الارز & \\
\hline 9,77 & $\Lambda \neg \Lambda, \vee \top ~$ & $\wedge r, \wedge q$ & ***0, or & $\cdot, 9 \leq V$ & 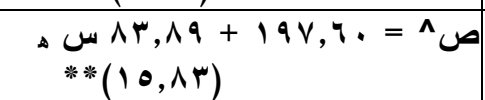 & الثامية & \\
\hline$V, V Y$ & $\tau r \wedge, 7$. & $\varepsilon q, r \mu$ & V & $\cdot, 974$ & 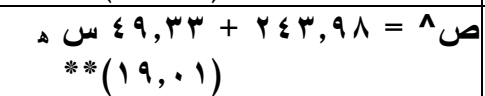 & البطاطس & \\
\hline$\ulcorner, \wedge$. & $r \uparrow \cdot, \wedge \Lambda$ & 9,94 & $* * 01, \leqslant 9$ & $\cdot, 97 \varepsilon$ & 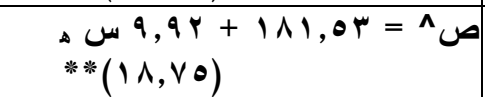 & الطماطم & \\
\hline 9,01 & $1 \cdot v \cdot, 91$ & $1 \cdot r, O V$ & $* * Y \backslash \wedge, \vee \wedge$ & $\cdot, 9 \leqslant \leq$ & 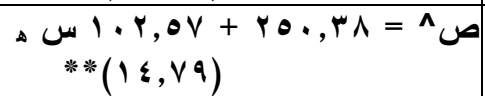 & القمح & \\
\hline $19, \wedge 1$ & $r \cdot T V, r V$ & $r \cdot \Sigma, Y_{0}$ & $* * r, 1, \vee \wedge$ & $\cdot, 949$ & 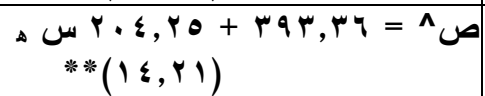 & الفول البلاى & \\
\hline$V, Y_{O}$ & | & $r \varepsilon \cdot, r T$ & $* * \vee Y, Y)$ & $\cdot, \wedge 0$. & $\begin{array}{l}\omega r \xi \cdot, r r+l r q r, I r=\Lambda \\
* * *(\wedge, \diamond q)\end{array}$ & العلس & لشتوية | لشت \\
\hline$r, r q$ & $r \backslash \Lambda, V Y$ & $V, \varepsilon 1$ & $* *\rceil,, 0$ & $\cdot, \wedge Y Y$ & 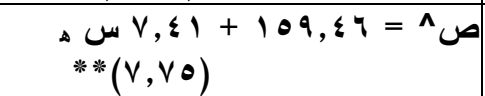 & البصل & \\
\hline
\end{tabular}

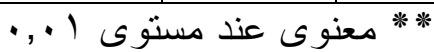

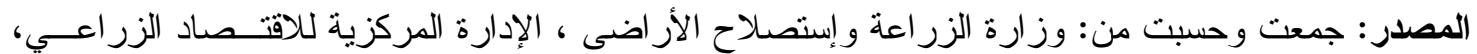
نشرة الإحصاءات الزر اعية، أعداد متفرقة.

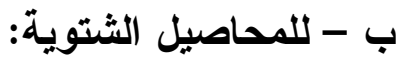

تشير نتائج الإتجاه الزمني العام لمتوسط تكلفة إنتاج الوحدة للمحاصيل الغذائيــة الــشتوية

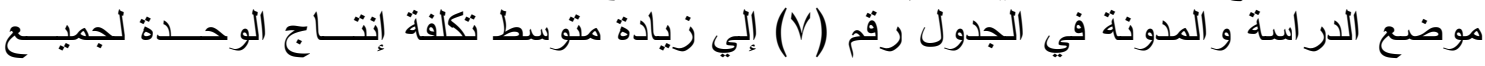

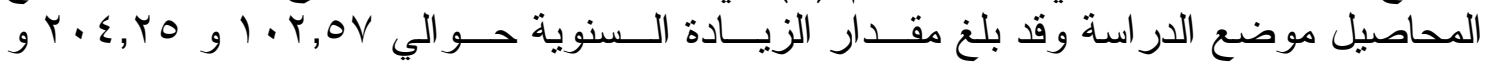

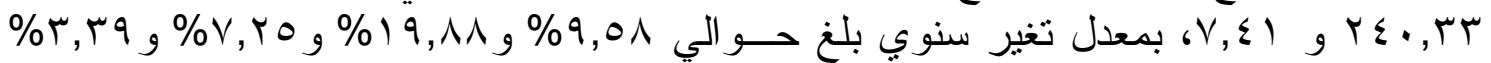

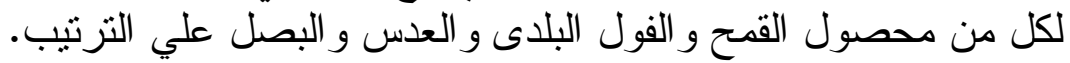

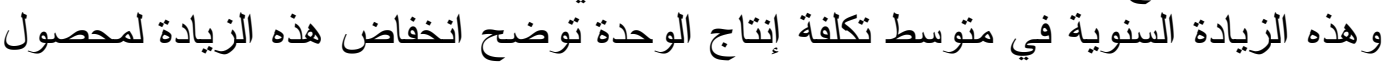

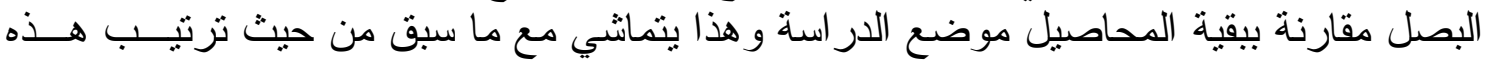

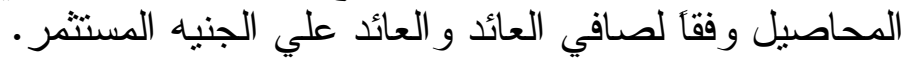

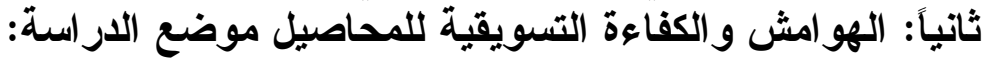

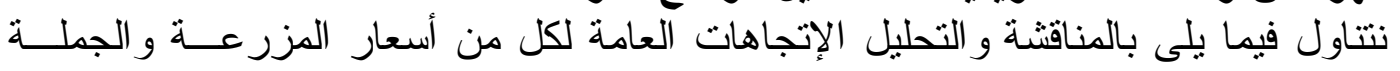

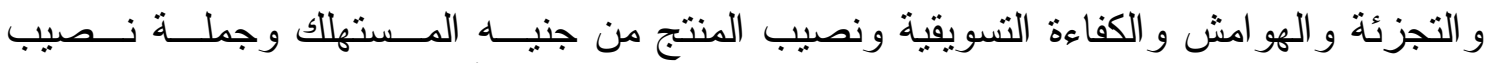

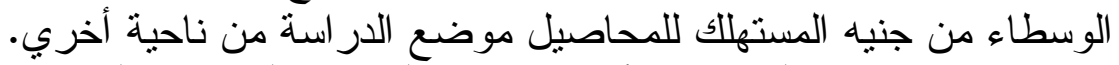

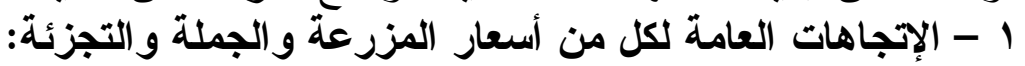

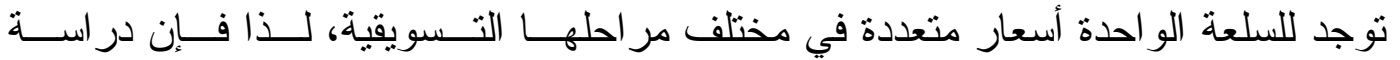

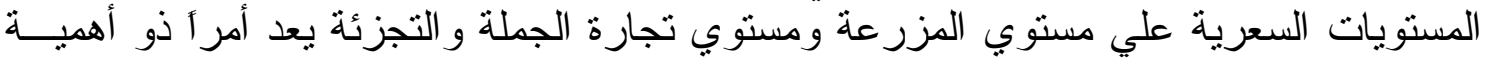

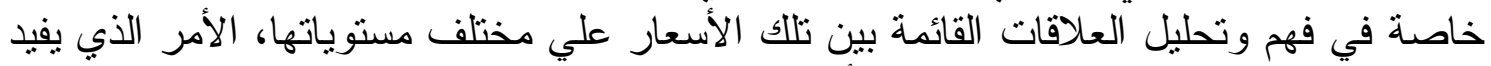

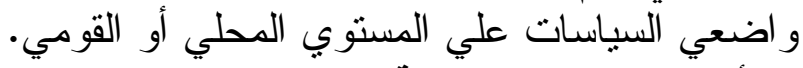
أ - للمحاصيل الصبفية: الصيان 


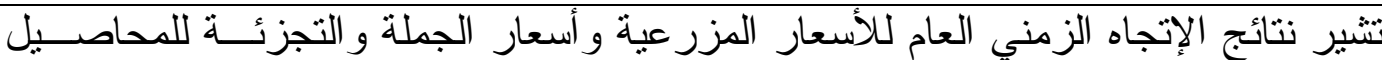

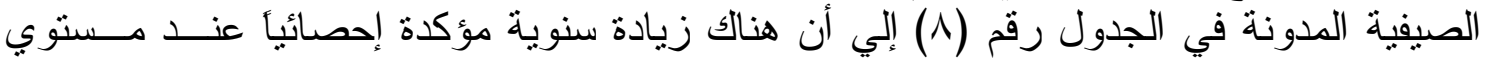

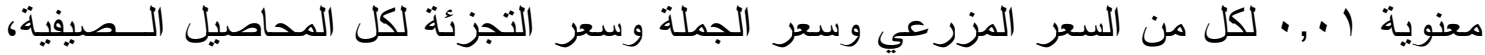

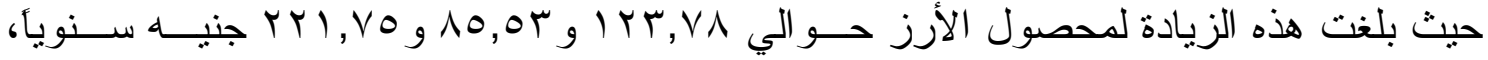

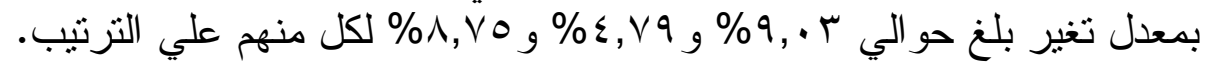

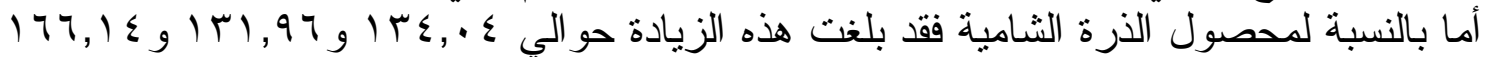

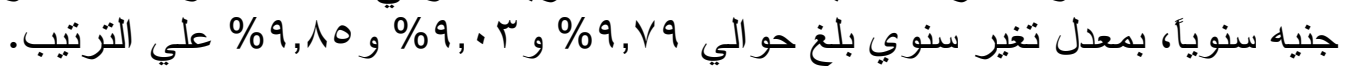

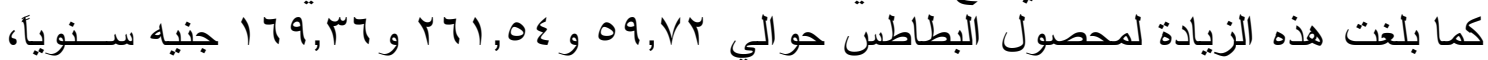

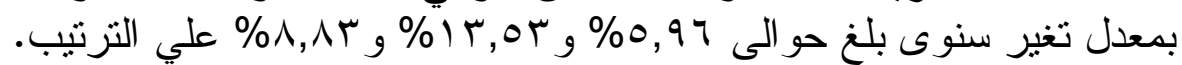

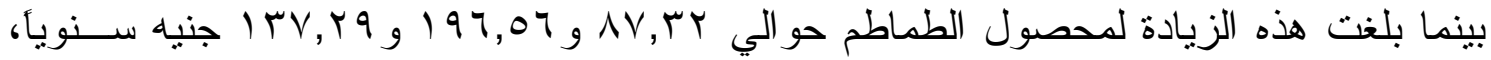

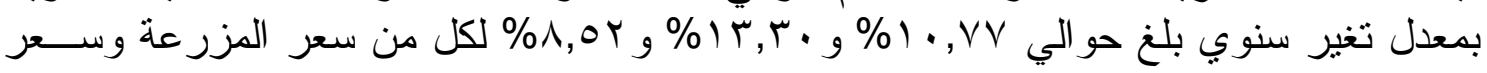
الجملة وسعر التجزئة علي الترنيب.

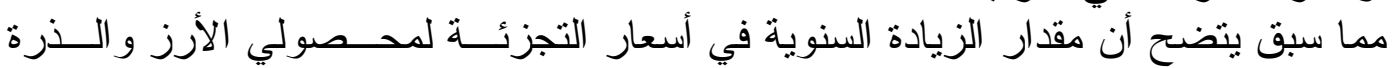

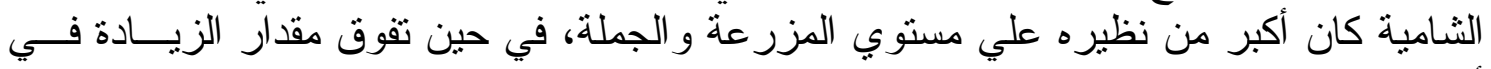

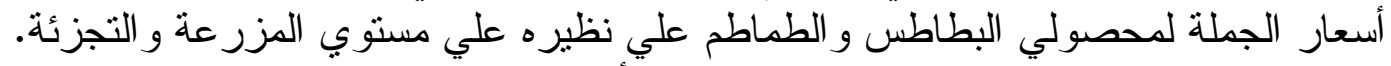

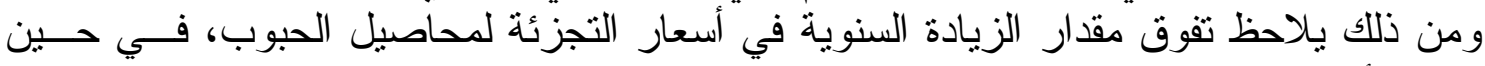

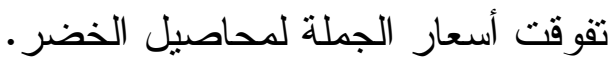

جدول رقم (^): نماذج الاتجاه الزمنى العام للأسعار المزرعية وأسعار الجملة والتجزئسـة للمحاصـيل

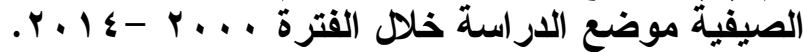

\begin{tabular}{|c|c|c|c|c|c|c|c|}
\hline التغيز معدل & المتوسط & مقدار & ف المحسوبة & ru & المعادلة & الأسعار & المحصول \\
\hline$q, \cdot r$ & $|r V|, \Sigma \varepsilon$ & IrT,VA & $* * \varepsilon Y, Y, Y 0$ & $\cdot, 9 V$ & 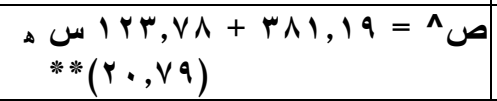 & 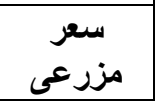 & \multirow{3}{*}{ أرز } \\
\hline$\varepsilon, \vee q$ & 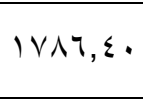 & 10,0r & $* * q, 1 r$ & $\cdot, \Sigma 1$ & 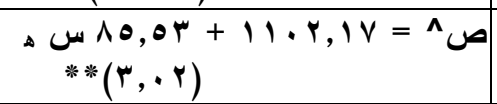 & سعر جملة & \\
\hline$\wedge, \vee \circ$ & rors,.. & YYI, Yo & $* * 1 \leq 9,7 r$ &., $9 r$ & 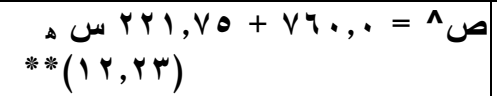 & سعر تجزئة & \\
\hline$q, \vee 9$ & Irד & $\mid T \varepsilon, \cdot \varepsilon$ & $* * \curlyvee \neg \wedge, \wedge \varepsilon$ & $\cdot, 90$ & 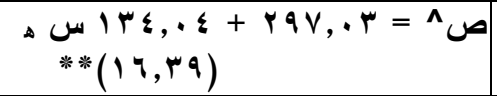 & 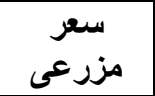 & \multirow{3}{*}{ 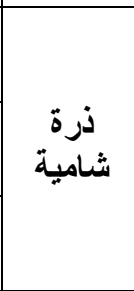 } \\
\hline$q, \cdot r$ & $\mid \leq 71,91$ & & $* * 1 \leq r, 19$ & $\cdot, 9 r$ & 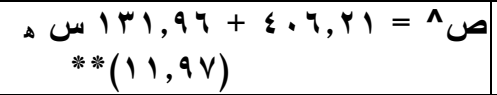 & سعر جملة & \\
\hline 9,10 & M T I I & $177,1 \leq$ & $* * \mid \tau, \pi)$ & .,94 & 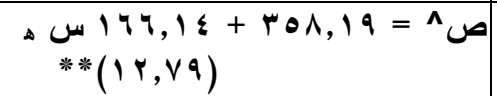 & سعر تجزئة & \\
\hline 0,97 & $1 \cdots 1, \varepsilon \varepsilon$ & $09, V Y$ & 0 ד, & $\cdot, V Y$ & 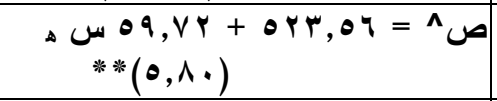 & مزرعى سعر & \multirow{3}{*}{ بطاطس } \\
\hline Ir,or & سז, & $r 71,0 \leqslant$ & $* * \nearrow 1,1 r$ & •, & 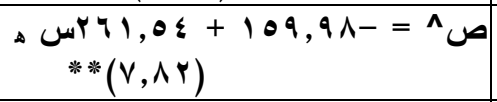 & سعر جملة & \\
\hline$\Lambda, \Lambda \mu$ & $1911,7 \vee$ & 179,17 & $* *) r \neg, r q$ & $\cdot, 91$ & $\begin{array}{l}\Delta(س 9, r q+\Delta \neg r, \Lambda 1=\wedge \\
* *(11, r \varepsilon)\end{array}$ & سعر تجزئة & \\
\hline $1 \cdot, V V$ & $\Lambda 1 \cdot, \varepsilon \varepsilon$ & AV,r & $* * 71,91$ & • & 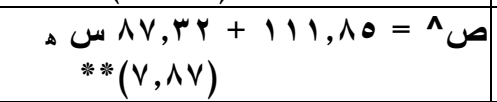 & مزرعى سعر & \multirow{3}{*}{ طماطم } \\
\hline . r. & $1 \leqslant \vee \wedge, r$. & 197,07 & $* * Y \leq, 00$ & $\cdot, 70$ & 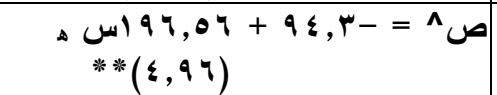 & سعر جملة & \\
\hline$\Lambda, O r$ & $171 \cdot, 7 \mathrm{~V}$ & IrV,rq & $* * \leqslant Y, 00$ & $\cdot, V \vee$ & 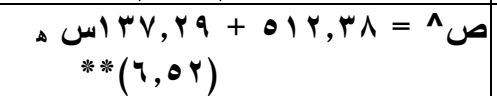 & 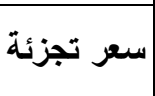 & \\
\hline
\end{tabular}




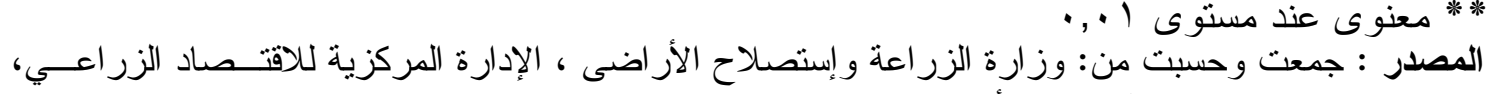
نشرة الإحصاءات الزر اعية، أعداد متقرقة. 


\section{ب - للمحاصيل الثتوية:}

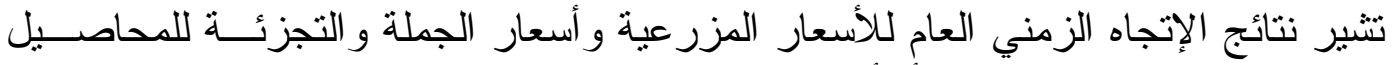

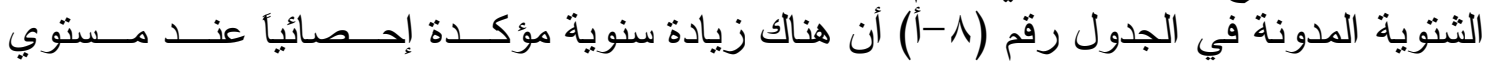

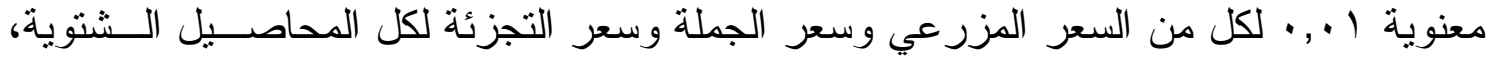

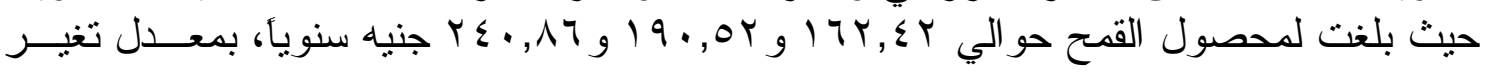

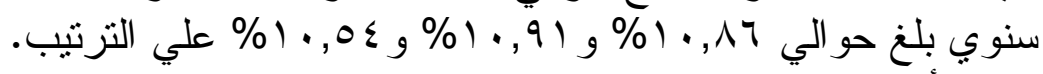

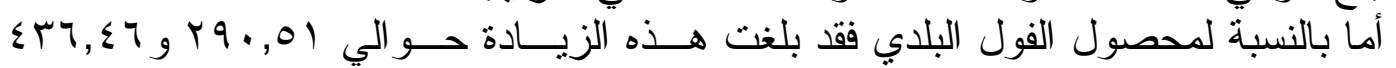

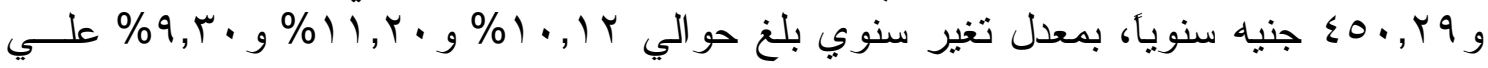
الترنيب.

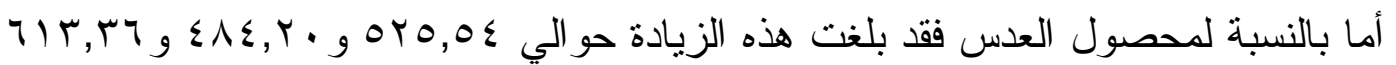

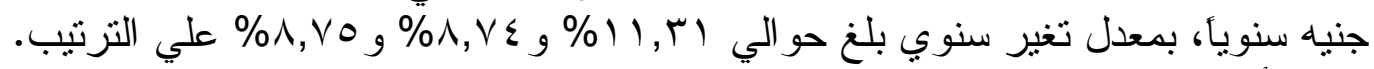

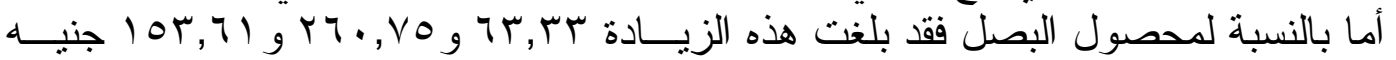

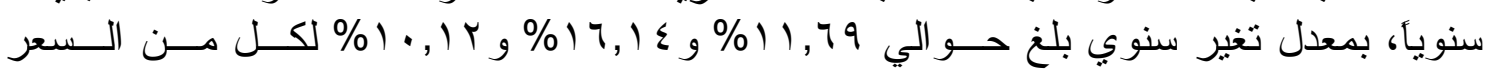

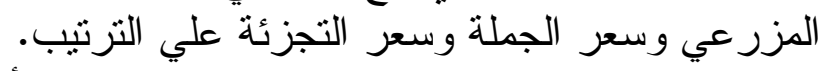

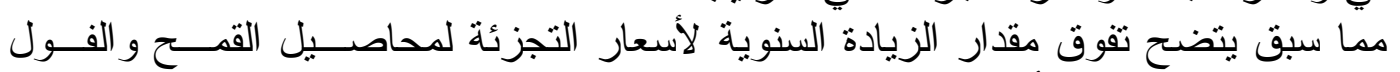

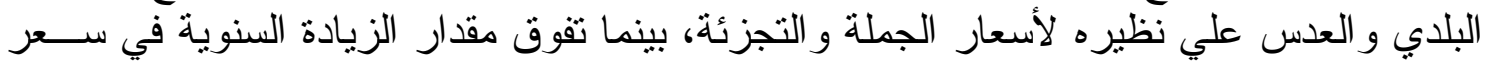

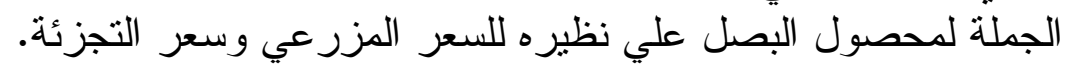

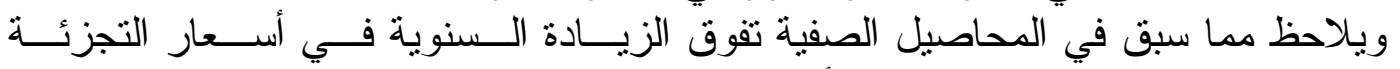

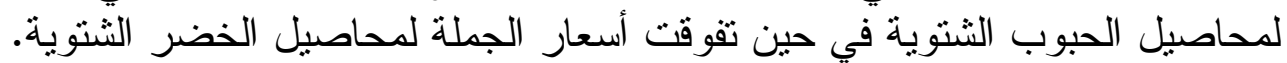
r - بهو امش التسويقية:

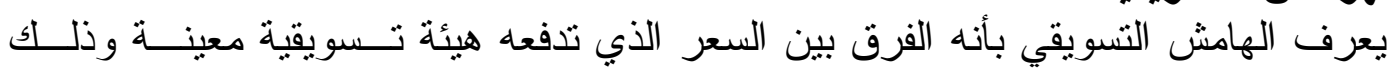

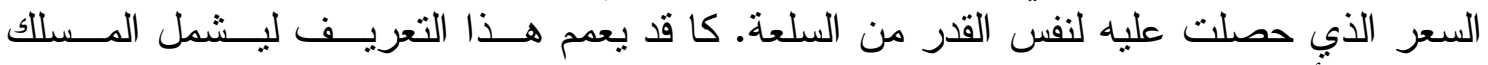

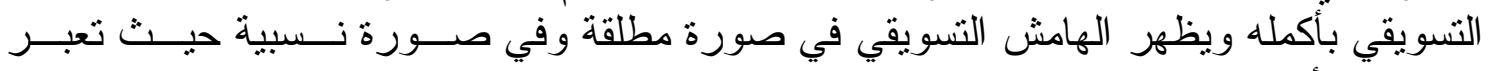

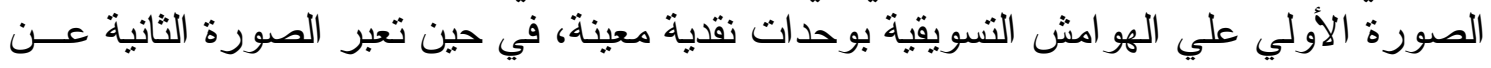
الهامش التسويقي المطلق منسوباً إلي سعر الأي البيع. أ - للمحاصيل الصيل الصيفية:

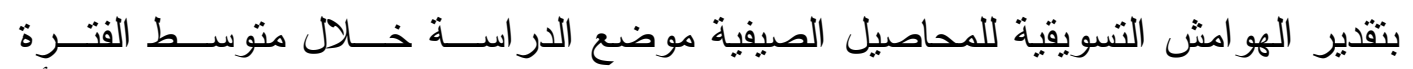

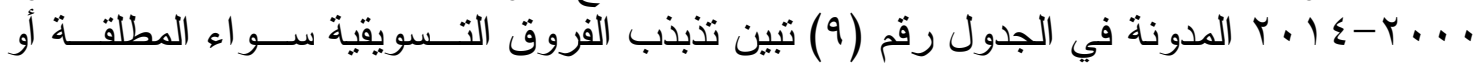

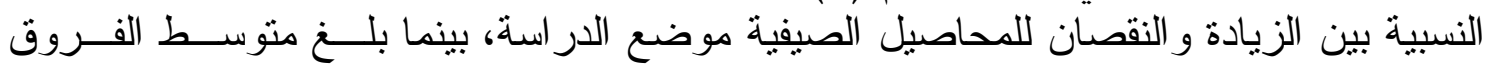

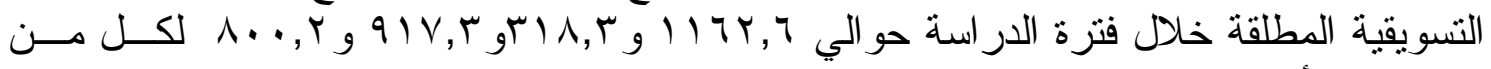

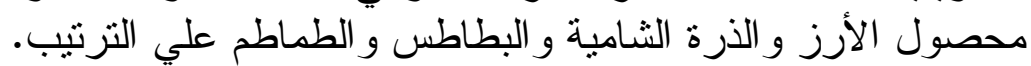

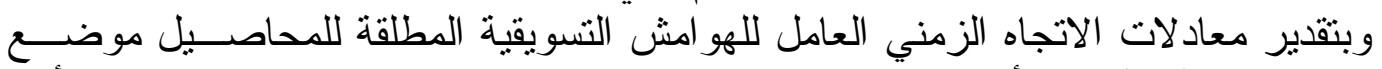

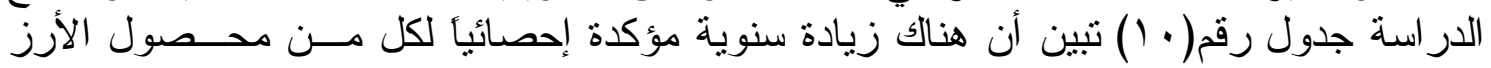

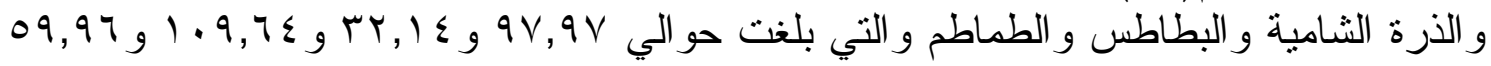

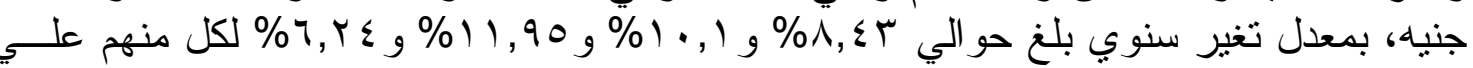
التزتيب. 
جدول رقم (^-أ): نماذج الاتجاه الزمنى العام للأسعار المزرعية وأسعار الجملة والتجزئة للمحاصـيل

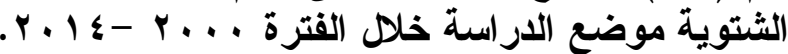

\begin{tabular}{|c|c|c|c|c|c|c|c|}
\hline التغير \%عدل & المتوسط & مقذار & ف المحسوبة & נر & المعادلة & الأسعار & المحصول \\
\hline $1 \cdot, \wedge 7$ & $1 \leqslant 97,19$ & $17 r, \varepsilon T$ & $* * 1 r q, O V$ & $\cdot, 94$ & 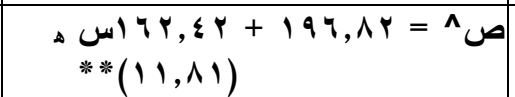 & مزرعى & \multirow{3}{*}{ قمح } \\
\hline $1 \cdot, 91$ & $\mid V \leq 7, \varepsilon$. & $19 \cdot$, or & $* * \mid r q, 00$ & $\cdot, 91$ & 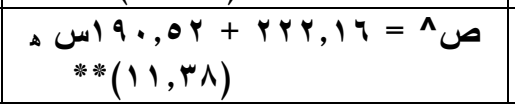 & سملة & \\
\hline $1 \cdot, 0 \leq$ & $I V \leqslant 7,7 \vee$ & $r \leqslant \cdot, \wedge T$ & $* * r) \wedge, r r$ & $\cdot, 97$ & 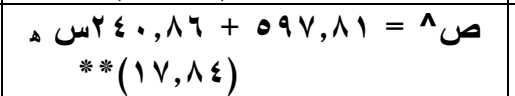 & تجزئة & \\
\hline $1 \cdot, 1 r$ & $r \wedge V \cdot, I r$ & $r q \cdot, 01$ & $* * Y Y \leq, T \leq$ & $\cdot, 90$ & 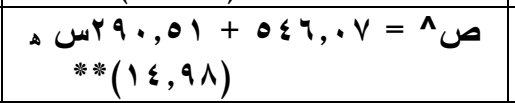 & مزرعى - معر & \multirow{3}{*}{ فول بلاى } \\
\hline $11, r$. & 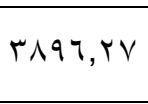 & \&rч, $\leqslant \uparrow$ & $* * 1 \leq \varepsilon, 70$ & $\cdot, 94$ & 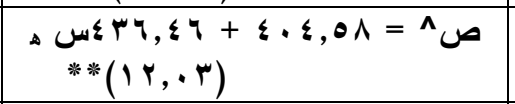 & سملة & \\
\hline$q, r$. & $\varepsilon \wedge \leq \varepsilon, \cdots$ & $\leqslant 0, r q$ & $* * \backslash \wedge \varepsilon, \Gamma \vee$ & . 94 & 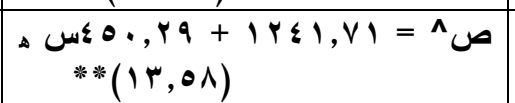 & تجزئة & \\
\hline $11, r 1$ & $\varepsilon \neg \leqslant \vee$, or & OYO,O & $* * \mid r \vee, q \wedge$ & $\cdot, 91$ & 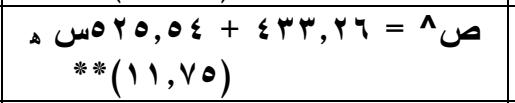 & مزرعى & \multirow{3}{*}{ عدس } \\
\hline$\Lambda, \vee \leqslant$ & $00 \leqslant \cdot, \varepsilon$. & $\varepsilon \wedge \varepsilon, Y$. & $* * \nearrow \curlywedge, \wedge \uparrow$ & $\cdot, \wedge \varepsilon$ & 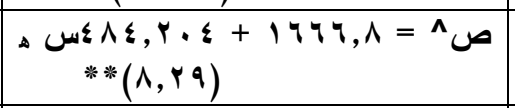 & جملة & \\
\hline$\Lambda, \vee \circ$ & V • . . & צז,זוד & $* * \Delta V, I V$ & • Ar & 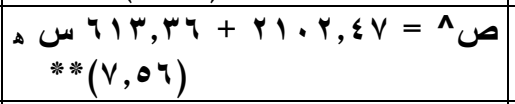 & تجزئة & \\
\hline 11,79 & $0 \leqslant 1, \wedge \vee$ & אז,זד & $* *\ulcorner q \varepsilon, r \wedge$ & $\cdot, 97$ & 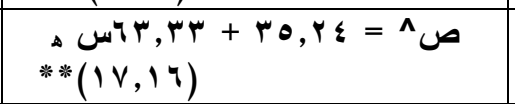 & مزرعى - م سعر & \multirow{3}{*}{ بصل } \\
\hline $17,1 \leq$ & $1710, \cdot V$ & $r T \cdot, V_{0}$ & $* * 09,09$ & • NT & 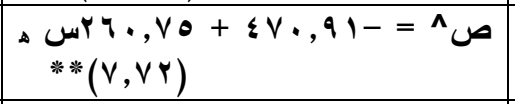 & سملة & \\
\hline $1 \cdot, 1 r$ & $1011, \ldots$ & 104,71 & $* * \vee \leq, \wedge 1$ & $\cdot, 10$ & ص^ = ص & تجزئة & \\
\hline
\end{tabular}

المصدر : جمعت وحسبت من: وز الزة الزر اعة و إستصلاح الأر اضــى ، الإدارة المركزيــة للاقتهــــاد الزر اعي، نشرة الإحصاءات الزر اعية، أعداد منقرقة.

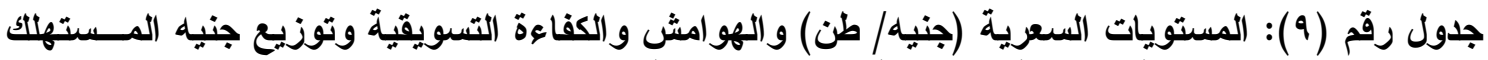

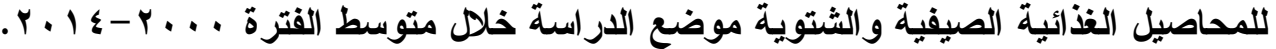

\begin{tabular}{|c|c|c|c|c|c|c|c|c|c|c|c|c|c|c|c|}
\hline \multicolumn{4}{|c|}{ توزيع جنيه المستهلك } & \multirow{4}{*}{ |لتسويقية } & \multicolumn{5}{|c|}{ الفروق أو الهوامش التسويقية } & \multirow{4}{*}{ |التجزئة . } & \multirow{4}{*}{ |الجمعة } & \multirow{4}{*}{ المنتج } & \multirow{4}{*}{ التكاليف } & \multirow{3}{*}{\multicolumn{2}{|c|}{ الححاص }} \\
\hline \multirow{3}{*}{ 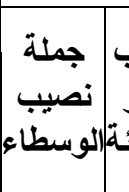 } & \multirow{3}{*}{ |نتجزئ } & & & & \multirow{2}{*}{\multicolumn{2}{|c|}{ |جملة - منتج الجملة }} & & & & & & \\
\hline & & & & & ئية - منتج|| & & تجزئة & & & & & & & & \\
\hline & & & & & | مطلقة 'نسياة & لكسية & 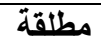 & & مطلقة 4 & & & & & & \\
\hline & ro, हT & $r \cdot, T$ & $0 \leqslant, 0$ & $\varepsilon 1,7$ & $\left.\sum 7, \cdot 117\right\}, 7$ & $r 0,2$ & $V \leqslant V, \cdot$ & Tr, & . $\{10,7$ & rors, & IVAV, & $|1| r v 1$, & $\{\Lambda \mid V, 0$ & الأرز & \\
\hline$\Lambda, \mathrm{V} \cdot$ & $11, \varepsilon$. & $V, r$. & $\Lambda 1, r$ & $V \varepsilon, \varepsilon$ & $\backslash \Lambda, \downarrow \Gamma \backslash \Lambda, \Gamma$ & 11,8 & YYO, \& & $Y, r$ & $9 Y, \Lambda$ & $17 \mathrm{NY}, \mathrm{r}$ & 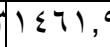 & a1r79, & ᄉ $4 \lambda$, & 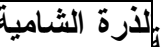 & \\
\hline 0,11 & $V, r$. & $r \Lambda, \cdot$ & $0 \varepsilon, 1$ & $\varepsilon r, \varepsilon$ & $\varepsilon 0, r q \backslash \vee, r$ & $\mathrm{r}, \mathrm{r}$ & $1 T, \mathrm{~V}-$ & $r 0,5$ & 494,0 & 14) & 7171, & $\eta 1 . .1$, & $T \mu \Lambda, 7$ & الب الب & \\
\hline ,,$\pi$ & $10, r$ & $r 0, r$ & $\leqslant 9, \xi$ & $r \varangle, \varepsilon$ & $0,, \sqrt{\wedge} \ldots, Y$ & 10,4 & $1, T, 0$ & 249, & . $4 \pi V, 1$ & & $1 \varepsilon$ & $\sqrt{11 \cdot, \varepsilon}$ & \begin{tabular}{|l|l|l}
$4 ., 9$ \\
\end{tabular} & الطماطم & \\
\hline . & $r \cdot, \pi$ & $9, \%$. & $09, y$ & 0,0 & $\{\cdot, \Gamma), r \lambda, 0$ & 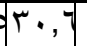 & VVA,Y & $1 \%$, & $\sqrt{r 0, Y}$ & rors, & $\sqrt{1 V \leqslant 7, \varepsilon}$ & (1) 1 १७, & $\pi 1 \cdot V \cdot$, & القمح & \\
\hline . & $\Gamma, \lambda$, & $19, v$ & 01,0 & $0 ., Y$ & $\{1,01$ & $A T, 1$ & $9 \leqslant \mathrm{~V}$, & & U1.rY, & & 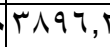 & $T \lambda$ & PYV, & 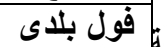 & \\
\hline 11 & $19,9$. & 17,4 & & $0 \wedge, 7$ & & 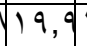 & & & $1 \cdot+,{ }^{4}$ & & & & |r|r|r, & علس & \\
\hline , & & $1, r$ & & $Y, 0$ & & , Y & & & & & & $0 \leqslant 1$ & 18 & عل مل & \\
\hline
\end{tabular}

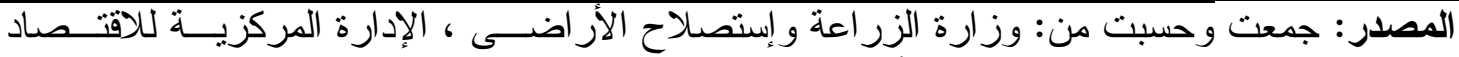
الزر اعي، بيانات غير منشورة، أعداد متفرقة. 


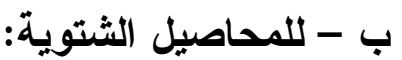

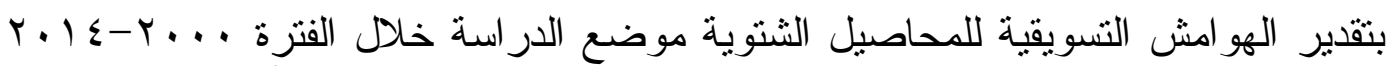

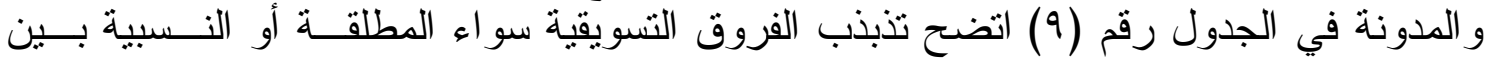

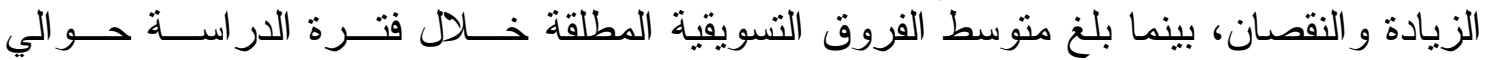

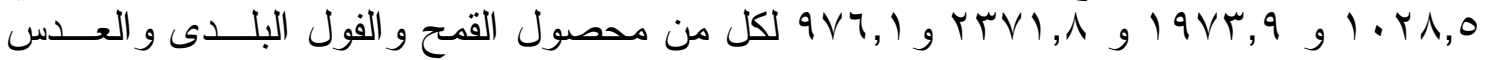

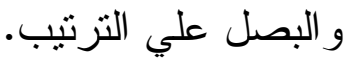

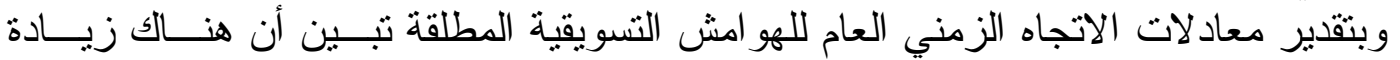

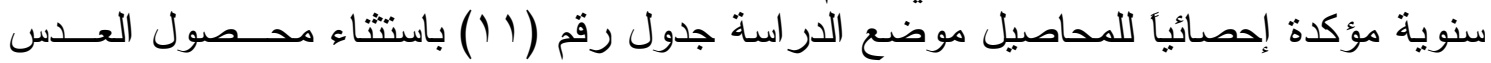

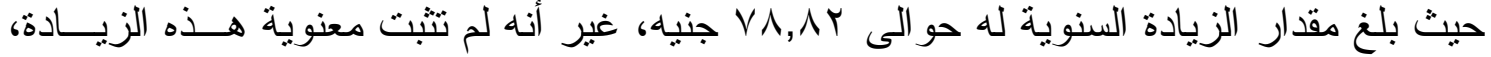

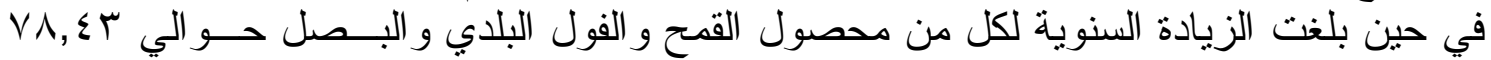

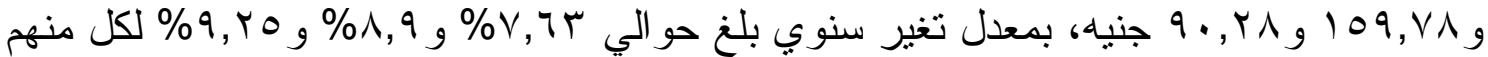
علي التزتيب.

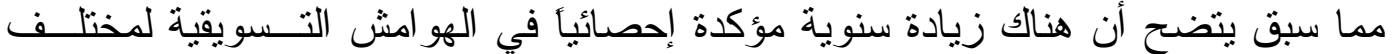

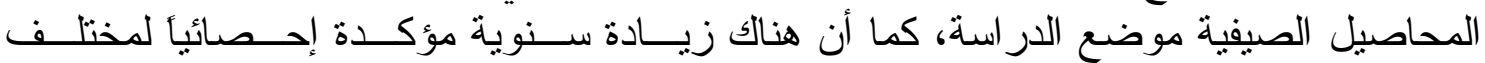
المحاصيل الثتوية باسنتناء محصول العدس لم تتبت معنوية الزيادة له. لهان. r - الكفاعة التسويقية

يمكن تعريف الكفاءة التسويقية بتعظيم النسبة بين المخرجات و المــدخلات حيــث تـشير

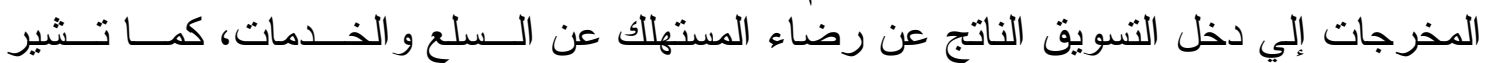

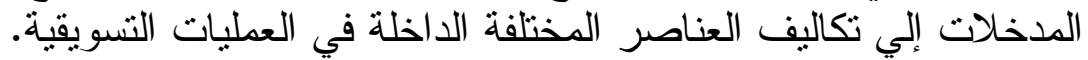

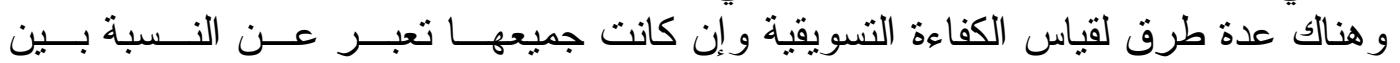

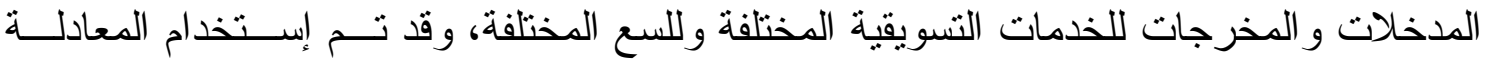
التالية لقياس الكفاءة التسويقية:

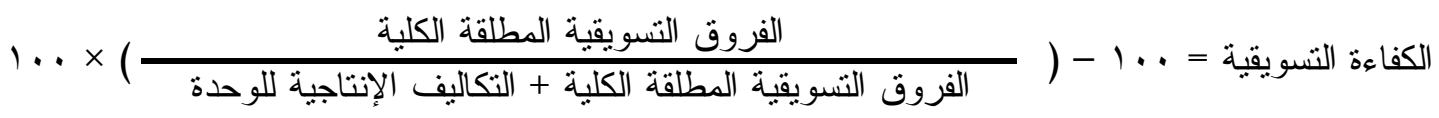

\section{أ - أ - للمحاصيل الصيفية:}

بتقدير الكفاءة التسويقية للمحاصيل الصيفية موضع الدية الدر اسة جدول رقم (9) خلادل الفتــرة

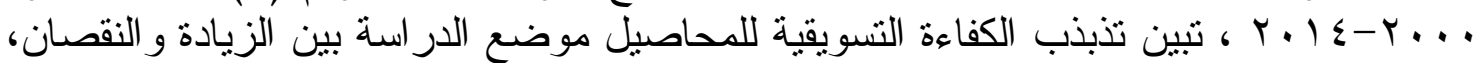

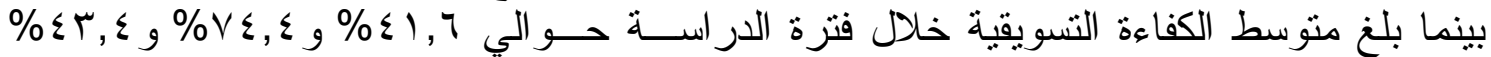

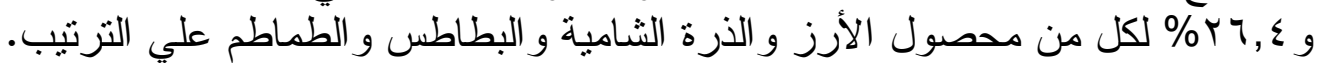

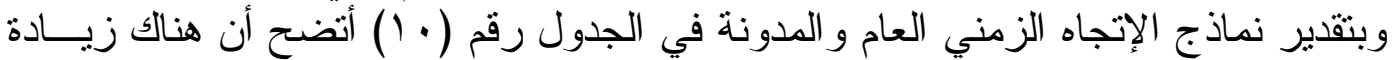

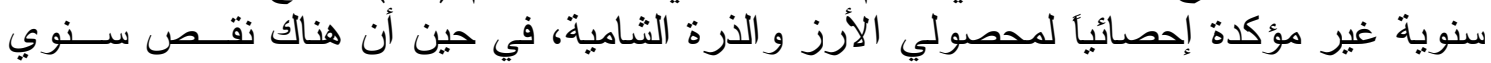
غير مؤكد إحصائياً لمحصولي البطاطس ولئاس والطماطم. 


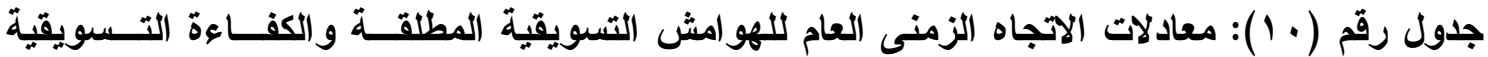

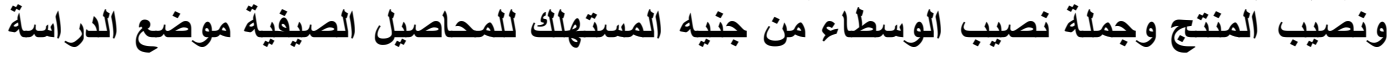

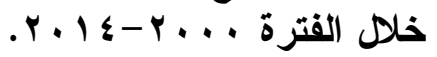

\begin{tabular}{|c|c|c|c|c|c|c|c|}
\hline التغير & المتوسط & مقدار & ف المحسوبة & ru & المعـــــــــــــــلة & \multicolumn{2}{|c|}{ المحتضير / الميل } \\
\hline$\Lambda, \varepsilon r$ & $117 r, 07$ & $9 V, 9 \vee$ & $* * r r, 90 r$ & $\cdot, V Y r$ & $\begin{array}{l}\Delta س \text { ص } ه \vee, q \vee \cdot+r \vee \wedge, \wedge 1 \cdot=\wedge \\
* *(0, \wedge r \vee)\end{array}$ & الأرز & \\
\hline $1 \cdot, 1 \cdot$ & MIN, Yo & $r, \mid \leq$ & $* * q, \ldots 1$ & $\cdot, \varepsilon \cdot q$ & $\begin{array}{l}\Rightarrow \omega r r, 1 \varepsilon+r 1,1 \leqslant=\wedge \\
* *(r, \ldots)\end{array}$ & 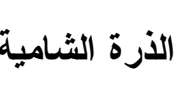 & \\
\hline 11,90 & qIV,r & $1.9,7 \leq$ & $* * r \wedge, 0 \uparrow$ & $\cdot, \mathrm{V} \leq \Lambda$ & 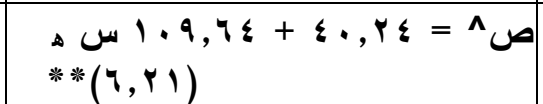 & البطاطس & \\
\hline $7, Y \leqslant$ & $\Lambda \cdots, r r$ & $\leqslant 9,97$ & $* \wedge, 79$ & $\cdot, \varepsilon \cdot 1$ & 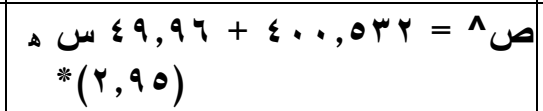 & الطماطم & \\
\hline- & - & • & •, rqV & $\cdot, \cdot r$. & 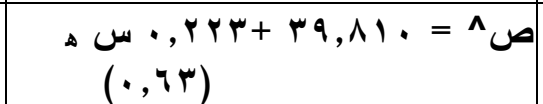 & الأرز & \\
\hline- & - & $\cdot, 107$ & $\cdot, 01$ & $\cdot, \ldots \varepsilon$ & $\begin{array}{l}\Delta س \cdot, 104+V Y, I Y=r= \\
(\cdot, Y Y V)\end{array}$ & 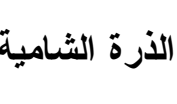 & \\
\hline- & - & $\cdot, \vee \vee 4-$ & $r, q \varepsilon$ & | & $\begin{array}{l}\Delta \cdot, \vee \vee \uparrow-\varepsilon q, \leqslant 0=\wedge \\
(1, q \wedge-)\end{array}$ & البطاطس & \\
\hline- & - & $\cdot, 01-$ & $r, \wedge \vee \leq$ & $\cdot,|\wedge|$ & 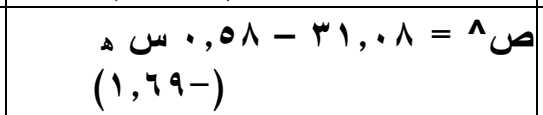 & الطماطر & \\
\hline- & - & $\cdot, \varepsilon \cdot \varepsilon$ & $1,1 \wedge \varepsilon$ & $\cdot, \cdot \wedge r$ & 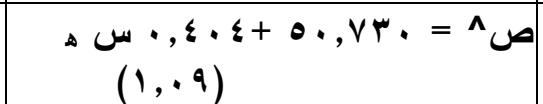 & الأرز & \\
\hline- & - & $\cdot, Y Y V$ & $\cdot, I V r$ & $\cdot, \cdot 1 T$ & 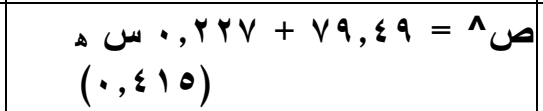 & 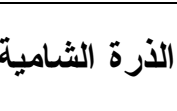 & نصيب \\
\hline$r, \varepsilon r$ & $0 \leqslant, \lambda 1$ & 1,r - & $* * \wedge, 9 \wedge \varepsilon$ & $\cdot, \varepsilon \cdot q$ & 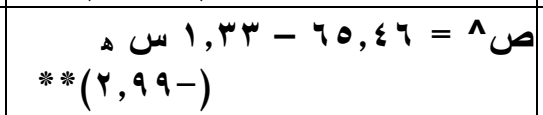 & البطاطس & \\
\hline- & - & $\cdot, \wedge 9 \leq$ & r, & $\cdot, 1 \wedge 9$ & 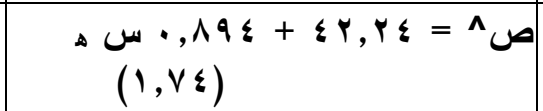 & الطماطم & \\
\hline- & - & $\cdot, \varepsilon \cdot r-$ & $1,1 \wedge \varepsilon$ & $\cdot, \cdot \wedge r$ & 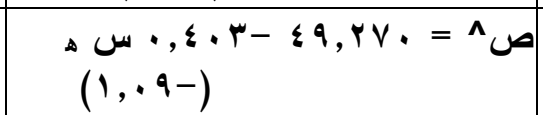 & الأرز & \\
\hline- & - & $\cdot, Y Y V-$ & $\cdot, I V T$ & $\cdot, \cdot 1 T$ & 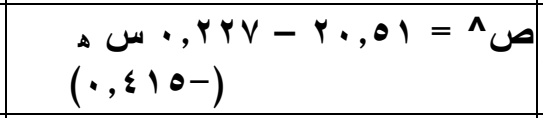 & الأزرة الشامية & نصيبة \\
\hline$r, q \leq$ & $\leqslant 0,19$ & מ & $* * \wedge, 9 \wedge \varepsilon$ & $\cdot, \varepsilon \cdot q$ & $\begin{array}{l}\Delta س \text { ص } 1, r r+r \leq, 0 \leqslant=\Lambda \\
* *(r, q 9)\end{array}$ & البطاطس & من المنتيه \\
\hline- & - & $\cdot, \wedge ৭ \cdot-$ & $r, \cdot r r$ & $\cdot, 1 \wedge 9$ & $\begin{array}{l}\Delta س \cdot, \wedge q \cdot-\Delta v, \vee \Delta=\wedge \\
(1, \vee \leqslant-)\end{array}$ & الطماطر & \\
\hline
\end{tabular}

المصدر : جمعت وحسبت من: وزارة الزر اعة و إستصلاح الأر اضـى ، الإدارة المركزيسـة للاقته صـاد الزر اعي، نشرة الإحصاءات الزر اعية، أعداد متفرقة. 


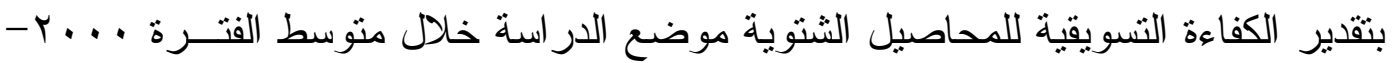

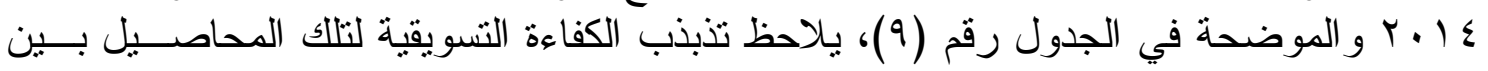

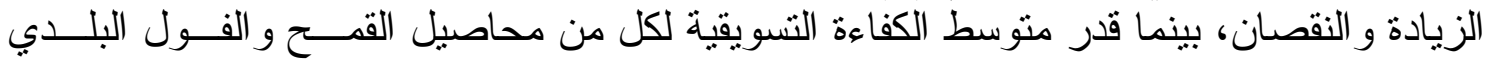

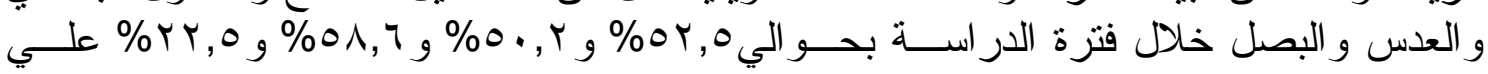
الترنيب.

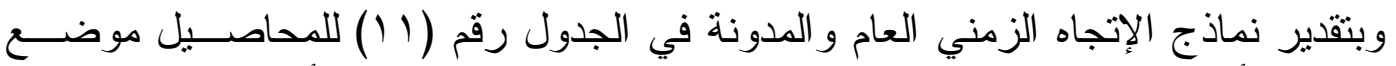

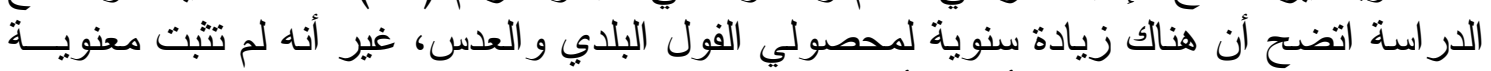

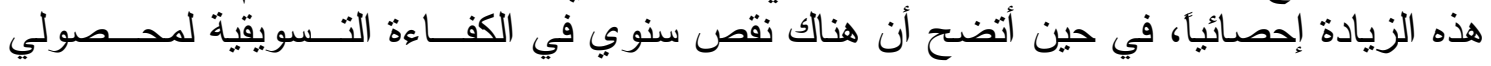

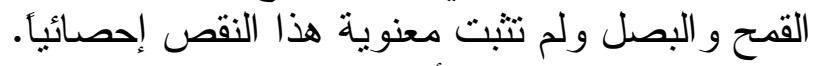

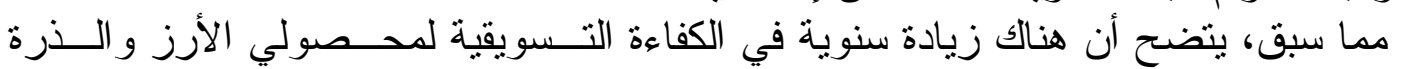

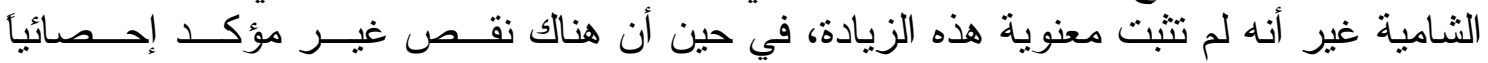
لمحصولي البطاطس و الطماطم. لتمبن.

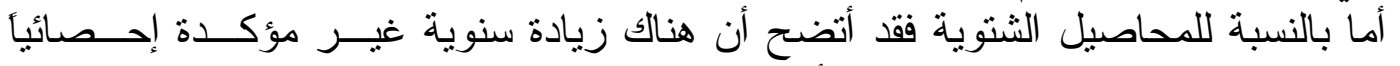

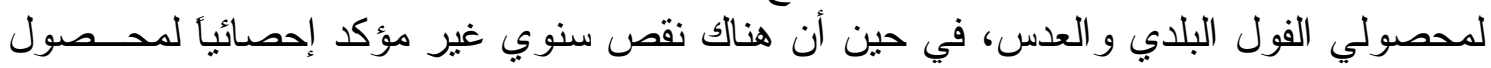

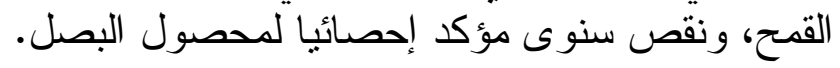
؛ - نصيب المنتج من جنيه المستهرئل

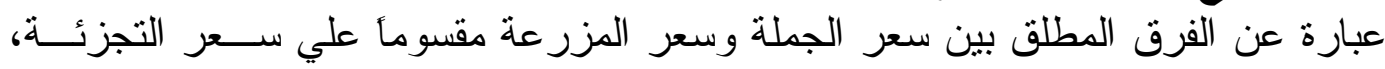

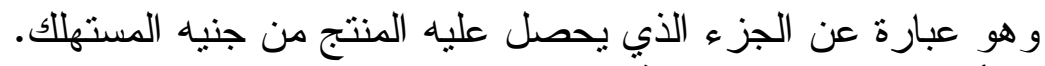

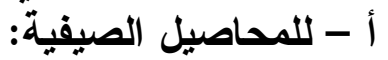

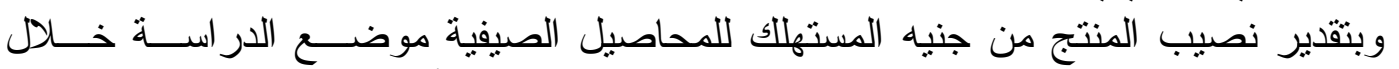

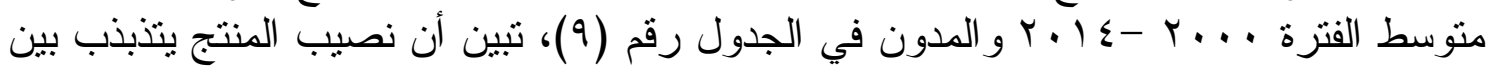

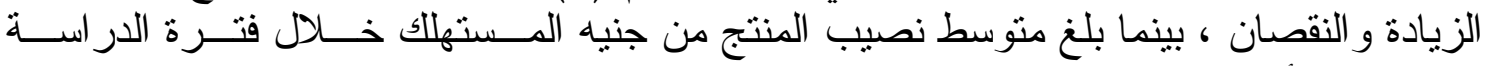

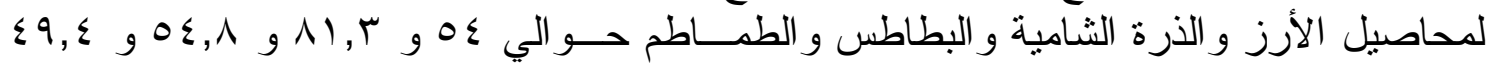
قرش لكل منهم علي الترتيب.

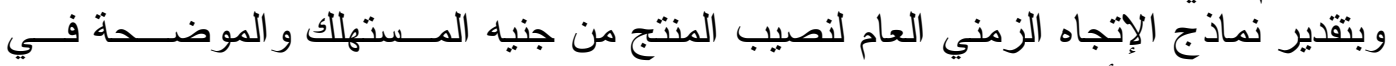

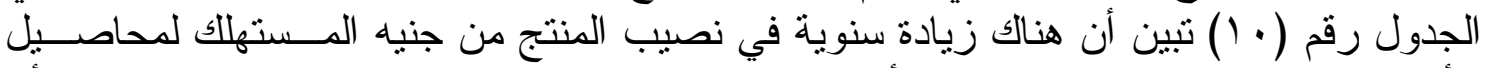

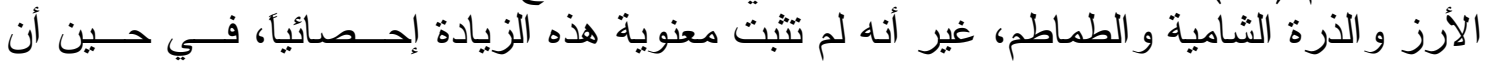

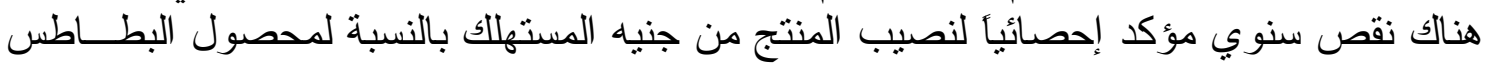

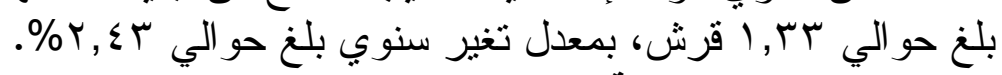

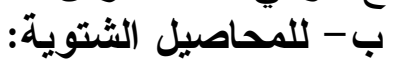

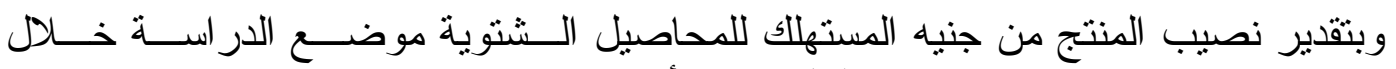

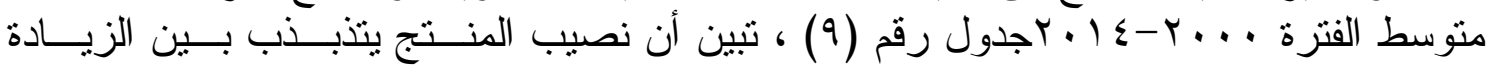

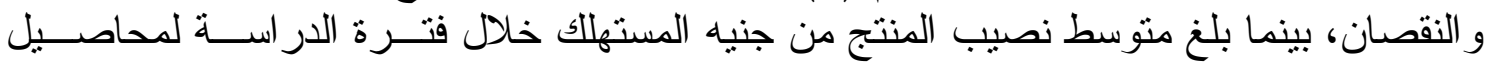

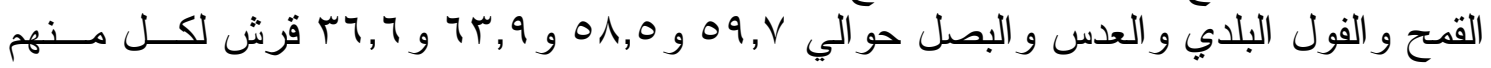
علي الترنيب. 
جدول رقم (11): معادلات الاتجاه الزمنى العام للهو امش التسويقية المطلقـــة والكفــــاءة التسـويقية

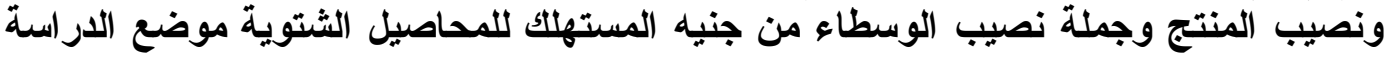

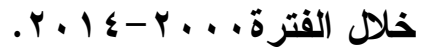

\begin{tabular}{|c|c|c|c|c|c|c|c|}
\hline التغير \% معدل & المتوسط & مقدار & ف المحسوبة & is & المعــــــــــــــــلة & \multicolumn{2}{|c|}{ المتغير } \\
\hline V,T & $1 \cdot r \wedge, \leqslant V$ & $\vee \wedge, \varepsilon r$ & $* * 17,97$ & $\cdot, 077$ & 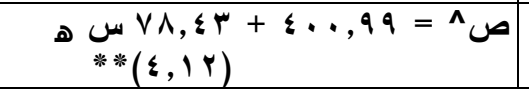 & القـح & \multirow{4}{*}{ الت التويقية } \\
\hline $1, \cdot 9$ & $19 \vee r, \wedge \wedge$ & $109, \vee \wedge$. & $* * r 1,1 \leq r$ & $\cdot, V \cdot Y$ & 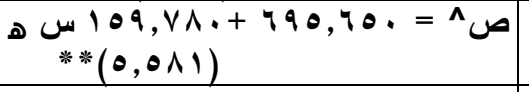 & |لفول البلدى & \\
\hline- & - & $\wedge V, \wedge r$. & $r, T \cdot r$ & $\cdot, 17 V$ & ص & 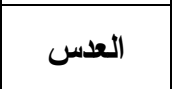 & \\
\hline $9, Y_{0}$ & $9 \vee 7,1 \%$ & $q \cdot, Y \wedge$ & $* * \curlyvee \wedge, \varepsilon \wedge r$ & $\cdot, T \wedge \vee$ & 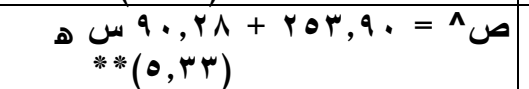 & البصل & \\
\hline- & - & •, Ү97- & $\cdot, 11$ & $\cdot, \cdot 1 \leq$ & 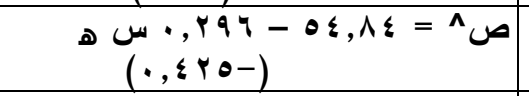 & القمح & \multirow{4}{*}{ التسويقية } \\
\hline- & - & $\cdot, 017$ & r, rOr & $\cdot, 1 \leqslant \wedge$ & 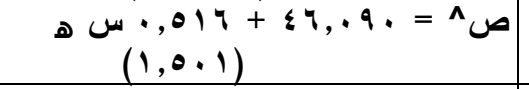 & الفول البلدى & \\
\hline- & - & $\cdot, \wedge r$. & r,qr. & $\cdot, 1 \wedge \varepsilon$ & 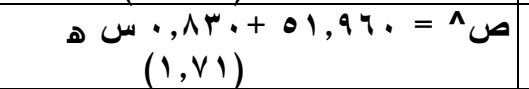 & العل العس & \\
\hline$v, 11-$ & $r, 0$ & $1,7 \cdot-$ & $* 0, \varepsilon r \leqslant$ & $\cdot, r 90$ & 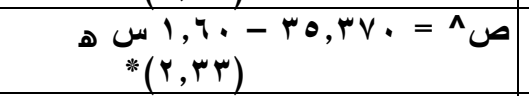 & البصل & \\
\hline- & - & $\cdot, \cdot \bullet \Sigma)$ & $\cdot, \cdots \varepsilon$ & $\cdot, \cdots r$ & 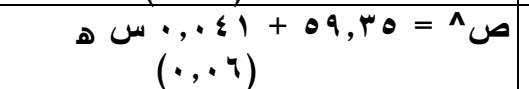 & القمح & \multirow{4}{*}{ من جنتيج } \\
\hline- & - & $\cdot, 70$. & $r, \Sigma Y_{1}$ & $\cdot, 10 \mathrm{~V}$ & ص = = . . & الفول البلدى & \\
\hline$r, 1$. & 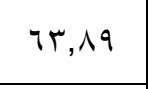 & $1,9 \wedge$. & $* *|r, Y \wedge|$ & $\cdot, 0.0$ & 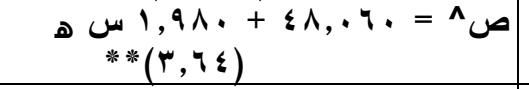 & العلس الع & \\
\hline- & - & ( & $\cdot, I A V$ & $\cdot, \cdot, 1 \leq$ & 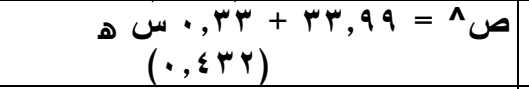 & البصل & \\
\hline- & - & $\cdot, \cdot, \leqslant \cdot-$ & $\cdot, \cdots \varepsilon$ & $\cdot, \cdots r$ & 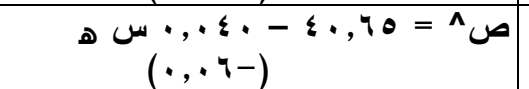 & القمح & \multirow{4}{*}{ المن جنيبة } \\
\hline- & - & $\cdot, 70 \cdot-$ & $r, \sum Y_{1}$ & $\cdot, 10 \mathrm{~V}$ & 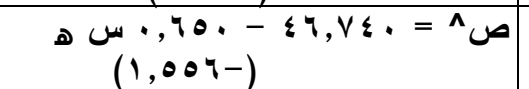 & الفول البلدى & \\
\hline $0, 乏 \wedge-$ & $r 4,11$ & $1,9 \vee \wedge-$ & $* *|r, Y \wedge|$ & $\cdot, 0.0$ & 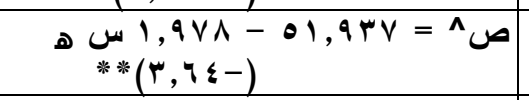 & 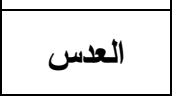 & \\
\hline- & - & - & $\cdot, I \wedge V$ & $\cdot, \cdot, 1 \leqslant$ & صـ = • • • • & البصل & \\
\hline
\end{tabular}

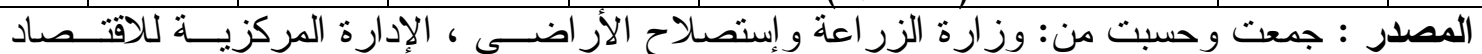

الزر اعي، نشرة الإحصاءات الزر اعية، أعداد متفرقة.

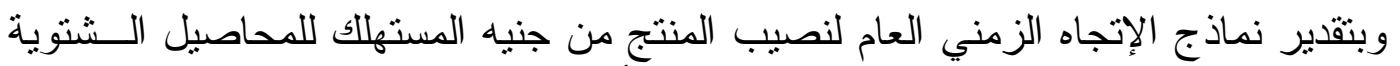

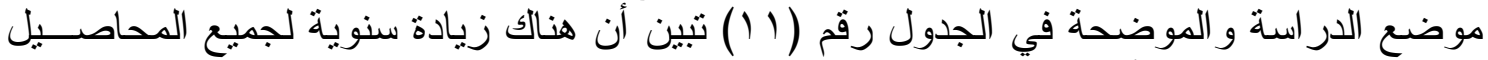

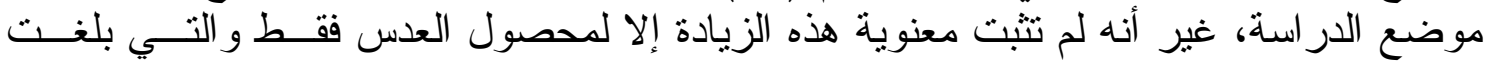

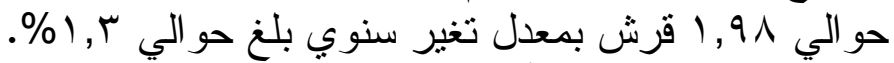

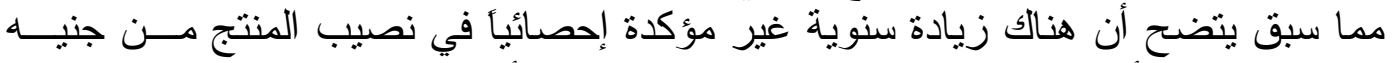

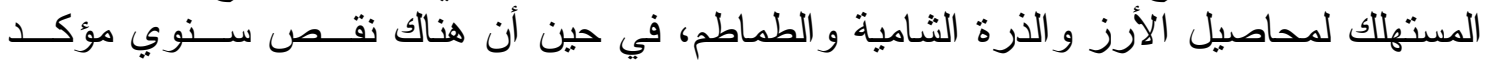
إحصائياً لمحصول البحاهيل الأطس ولإن.

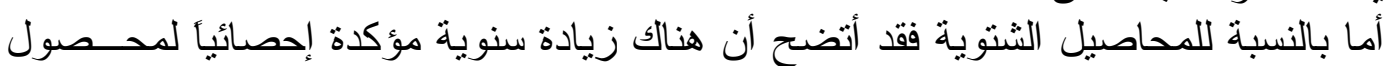
العدس، في حين لم تتأكد إحصائياً معنوية الزيادة لمحاصيل القمح و الفول البلدي و البصل 


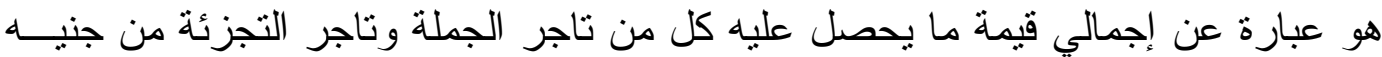

\section{أ - ل أمحاصيل الصيفية:}

بتقدير جملة نصيب الوسطاء من جنيه المستهلك للمحاصيل الصيفية موضع الدر اسة خلاهل

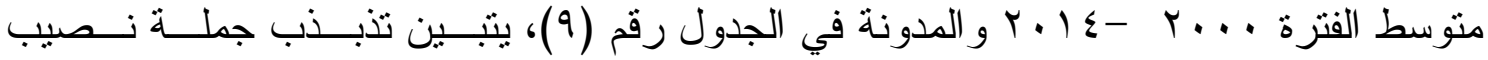
الوسطاء بين الزيادة و النقصان خلال فترة الدر اسة، بينما قدر منوسط جملة نصيب الوسطاء مسـن

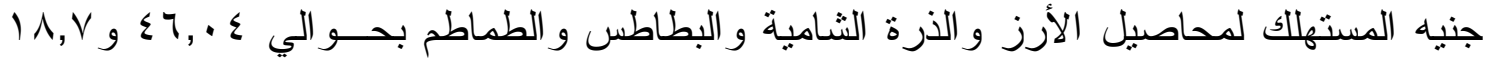

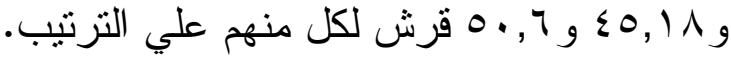

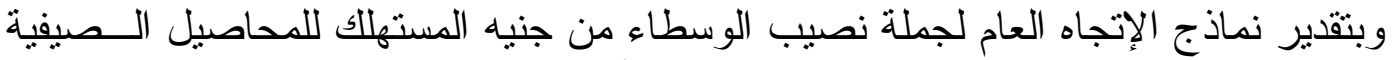

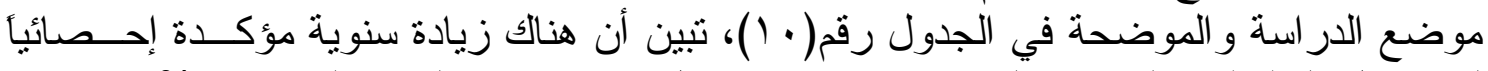

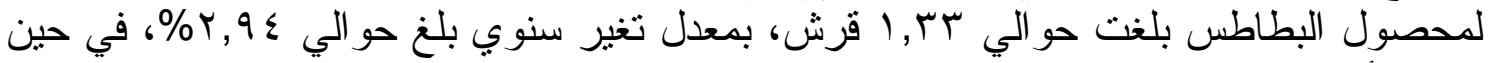

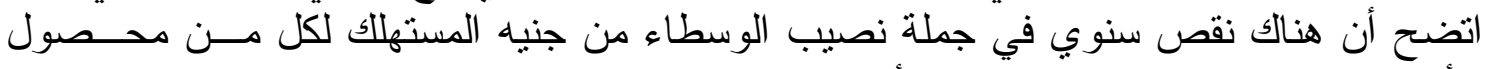

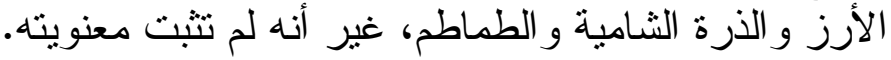

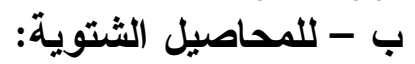

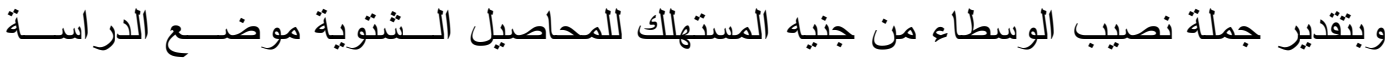

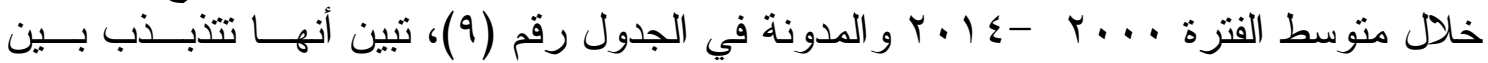

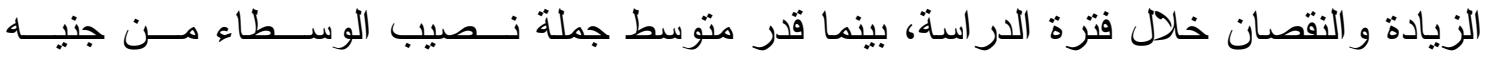

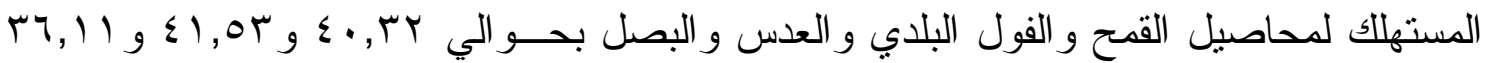
و إ, آ قرش لكل منهم علي الترنيب. وبتقدير نماذج الإتجاه الزمني العام لجملة نصيب الوسطاء من جنيه المستهلك للمحاصــيل

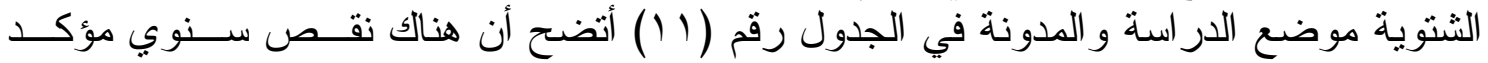

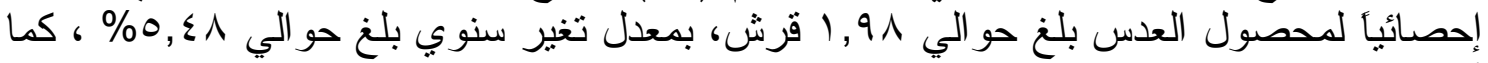

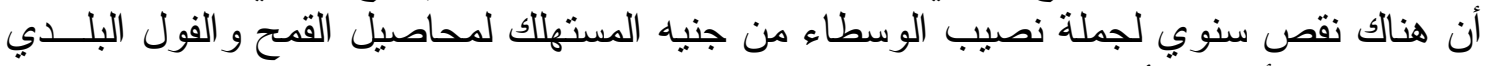

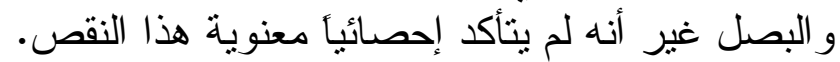

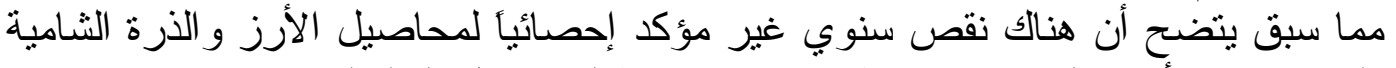
و الطماطم، في حين أن هنالك زيادة سنوية مؤكدة إحصائياً لمحصول نهوئ البطاطس.

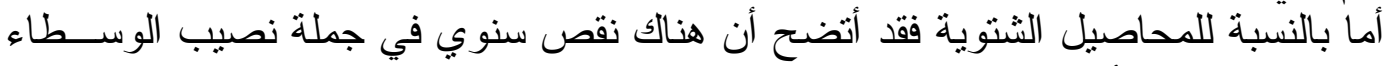

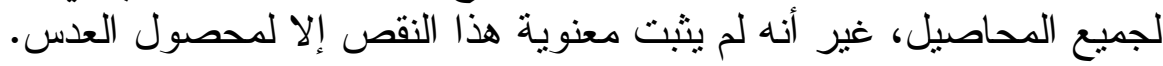
التتائج والتوصيات المديات ا-وجود فروق معنوية مؤكدة إحصائياً بين صافي العائد الفداني السنوي و الثهري و العائد علي

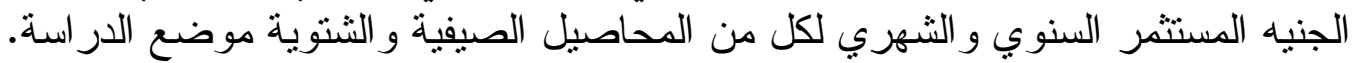

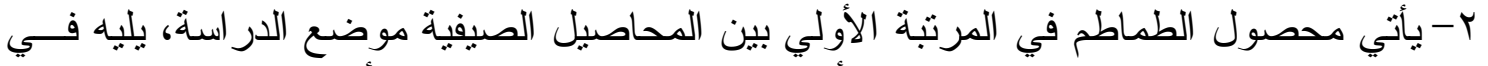

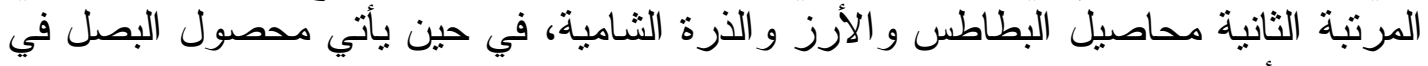

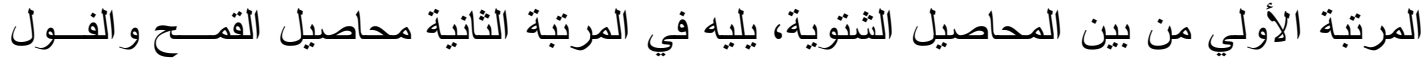

$$
\text { البلدي و العدس. }
$$

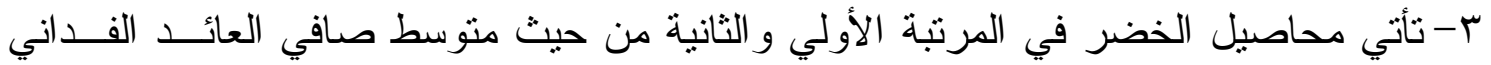

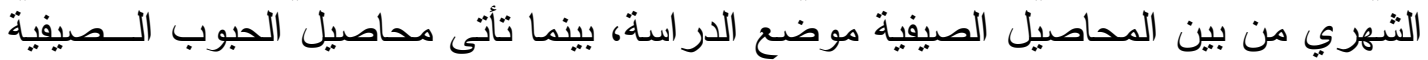

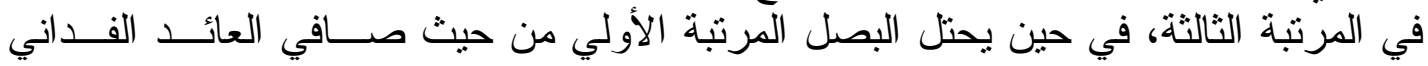

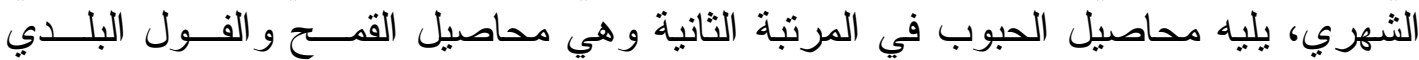


ع- يأتي محصول الطماطم في المرتبة الأولي بين المحاصيل الصيفية موضع الدر اسة من حيث

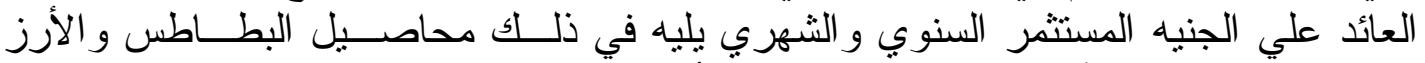

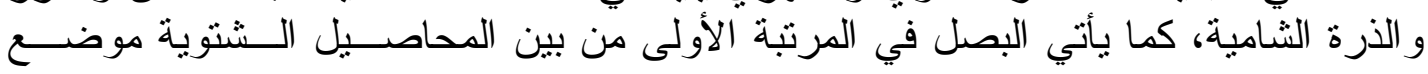

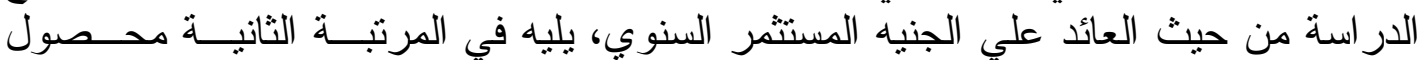

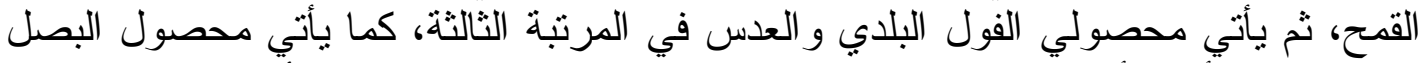
في المرتبة الأولي أيضاً من حيث العائد علي الجنيه المستثمر / شهر، ثم تأني بقية المحاصيل الشتوية موضع الدر اسة في المادية المرتبة الثانية. 0-وجود زيادة معنوية مؤكدة إحصائيًا لمتوسط تكلفة إنتاج الوحدة للمحاصيل الصيفية و الثنتوية

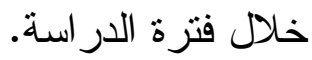
؟-وجود زيادة مؤكدة إحصائيًا في كل من الأسعار المزرعية وأسعار الجملة وأسعار التجزئسـة

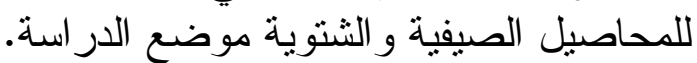

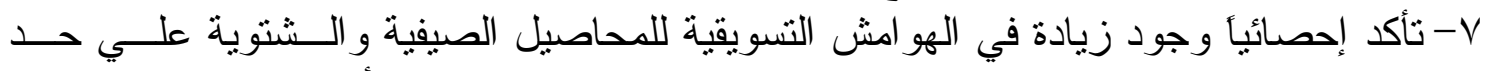

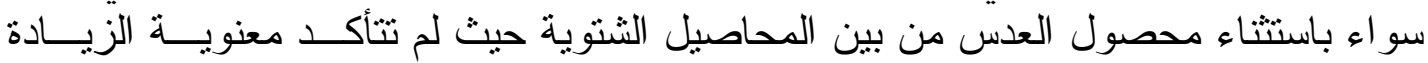
إحصائياً.

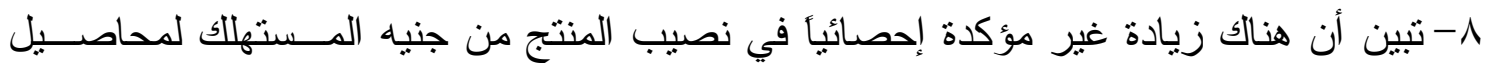

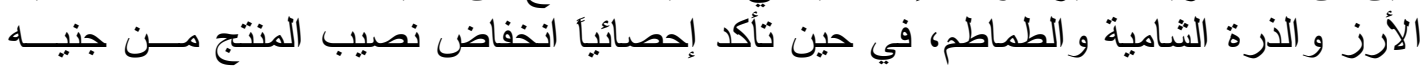

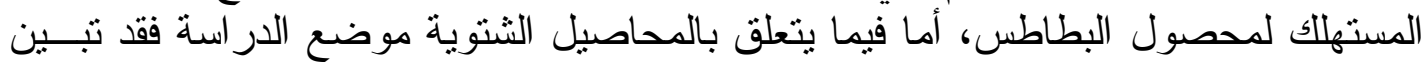

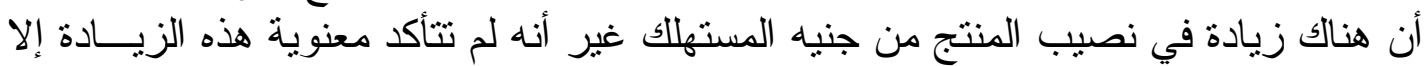

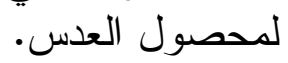

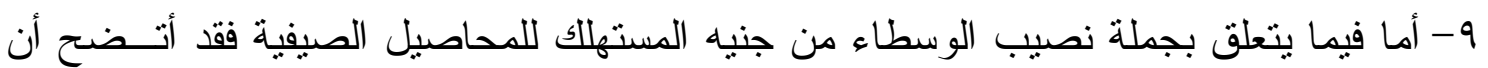

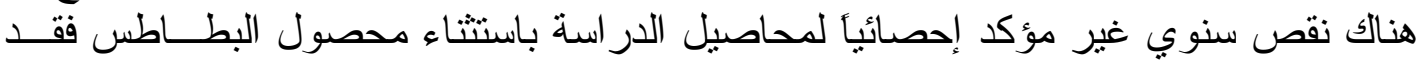

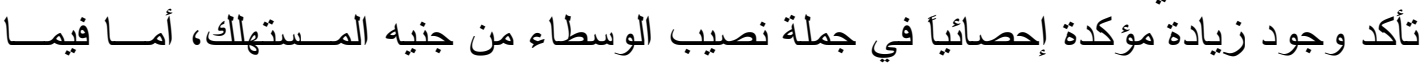

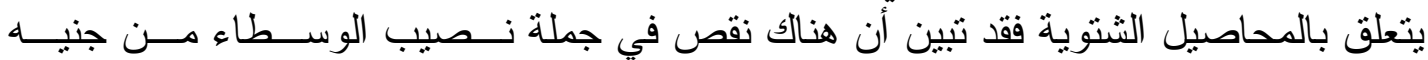

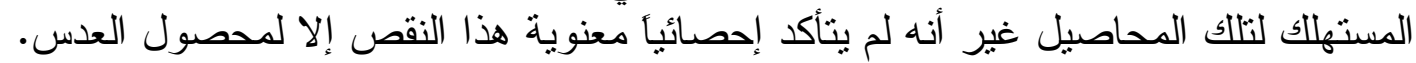

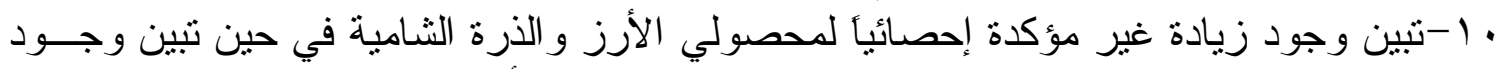

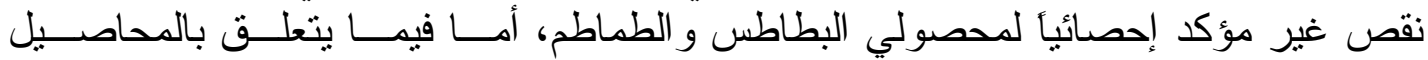

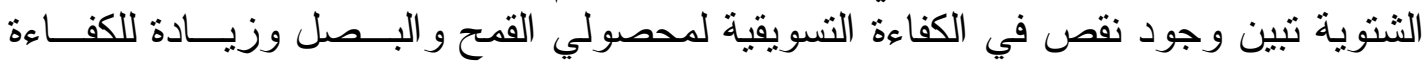

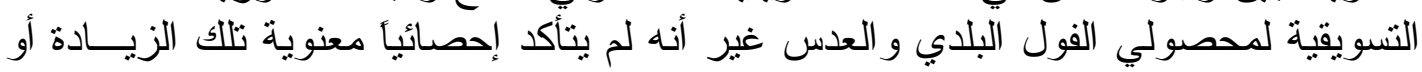
النقص.

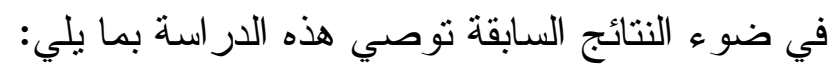
1-ضرورة نو افر المعلومات التسويقية للزراع حتي يمكنهم الحصول علي أســعار مناســبة

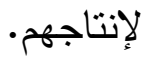

ץ- الإهتمام بتحسين الكفاءة التسويقية لكل من المحاصيل الصيفية و الثنتوية موضع الدار استــة

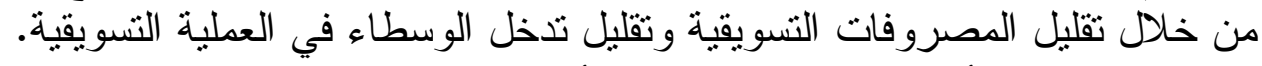

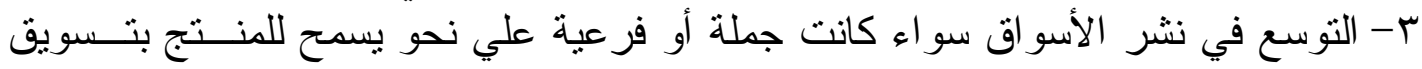

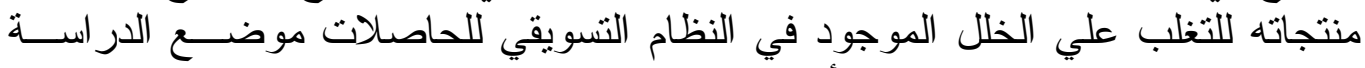

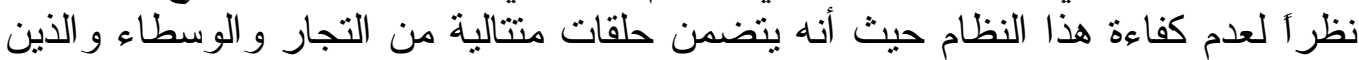
يحققون أرباح طائلة علي حساب المنتج. 


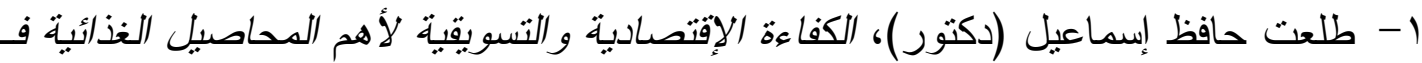

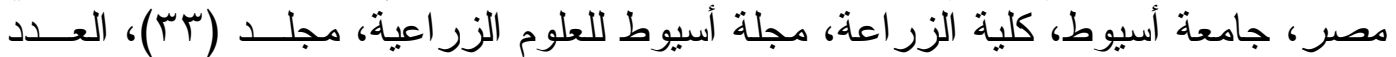

.r.. r ، ( $(\varepsilon)$

r- طلعت حافظ إسماعيل (دكتور)، محمد عبد الوهاب أبو نحول (دكتور)، المستويات السعرية

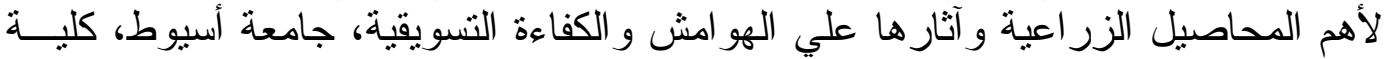

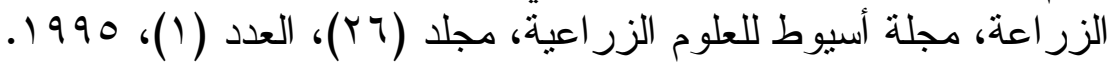

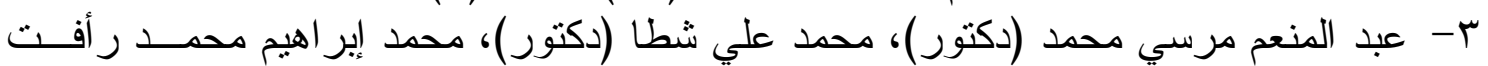

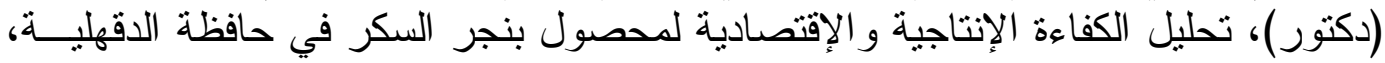

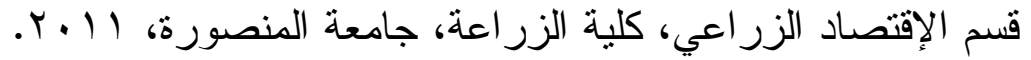

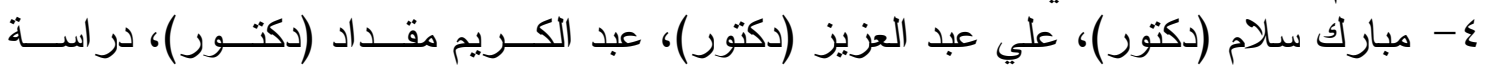

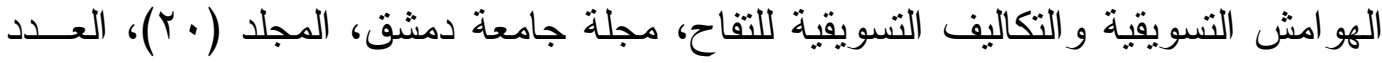

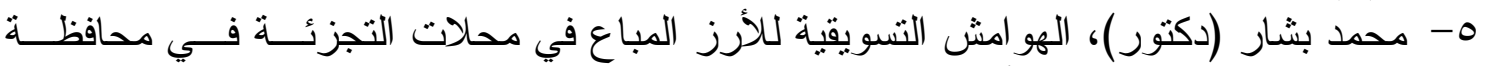

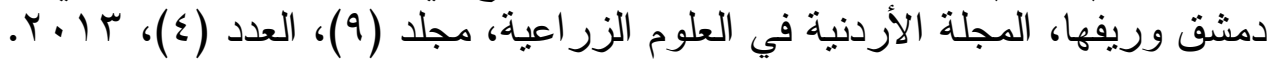

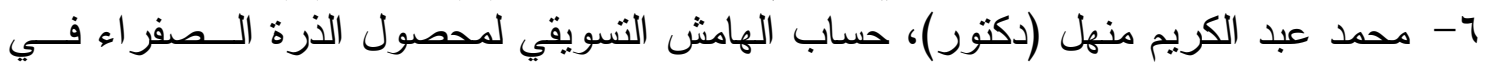

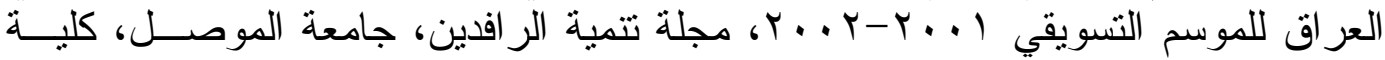

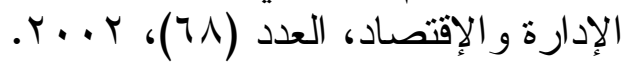

الملخص الإل

استهدف هذا البحث التعرف علي الكفاءة الإقتصادية للمحاصيل الغذائية الصيفية و الثشتوية

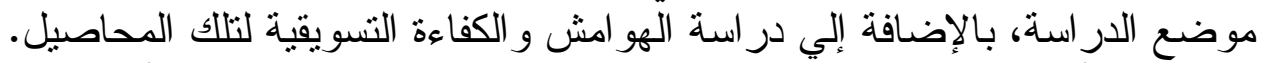

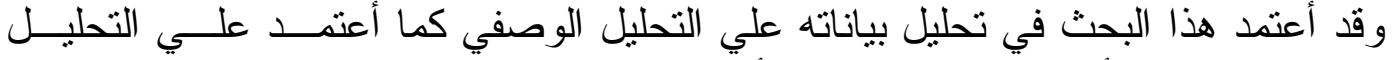

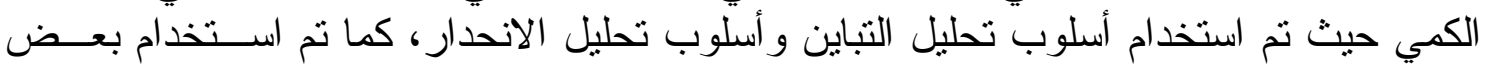

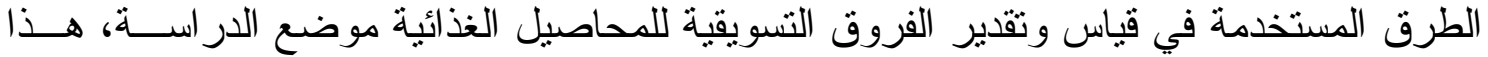

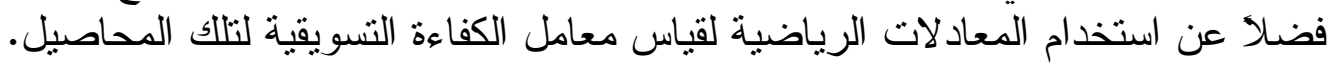

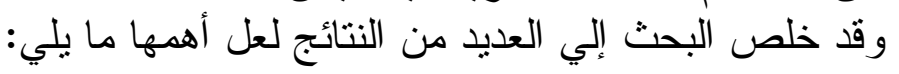

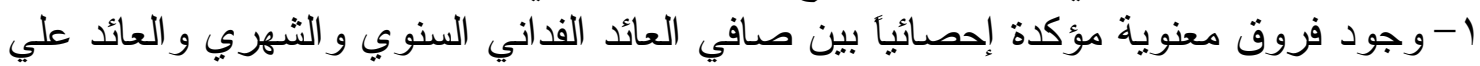

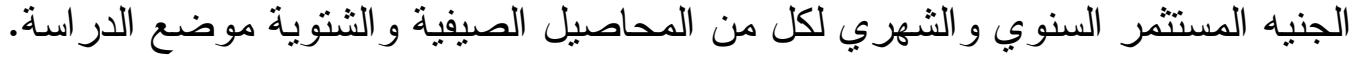
ץ-وجود زيادة معنوية مؤكدة إحصائياً لمتوسط تكلفة إنتاج الوحدة للمحاصيل الصيفية و الثتوية خلال فتزة الدر اسة.

ب-وجود زيادة مؤكدة إحصائيًا في كل من الأسعار المزرعية وأسعار الجملة و أسعار التجزئــة

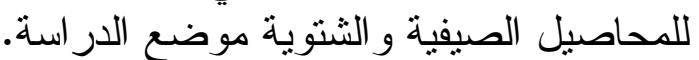

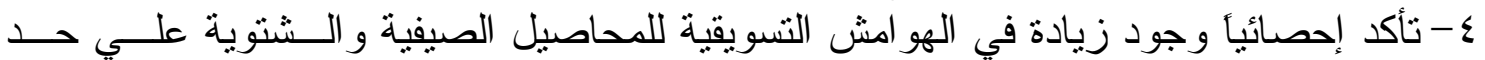

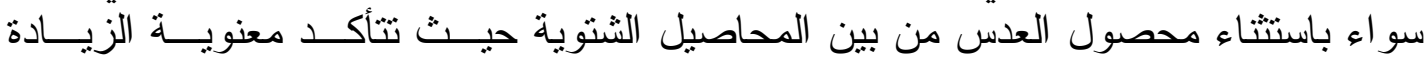
إحصائياً.

0- تبين أن هناك زيادة غير مؤكدة إحصائياً في نصيب المنتج من جنيه المـستهلك لمحاصــيل

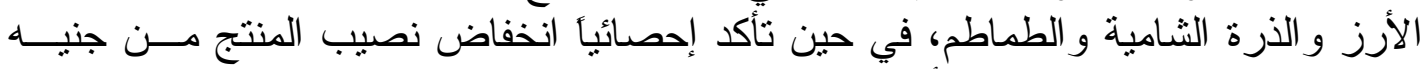

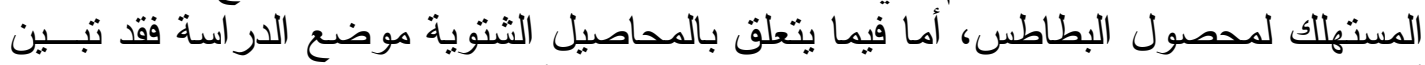

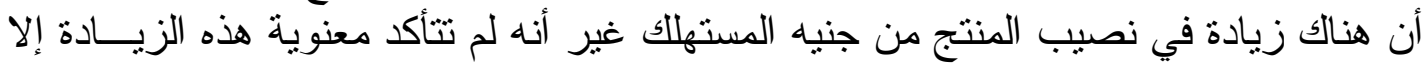
لمحصول العدس. 
؟- أما فيما يتعلق بجملة نصيب الوسطاء من جنيه المستهلك للمحاصيل الصيفية فقد أتـضح أن فئن

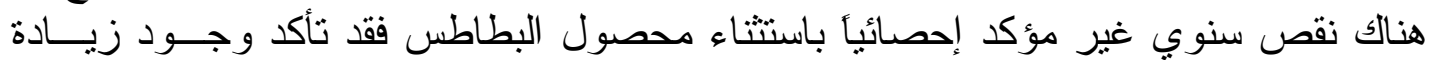

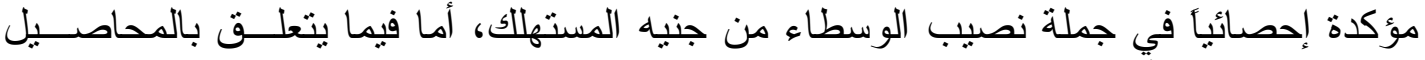

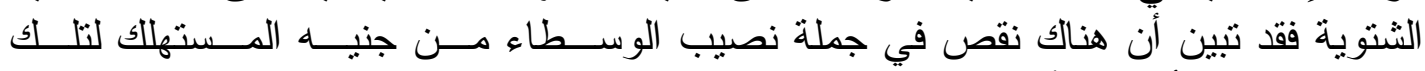
المحاصيل غير أنه لم يتأكد إحصائياً معنوية النقص إلا لمحصول فئ العدس.

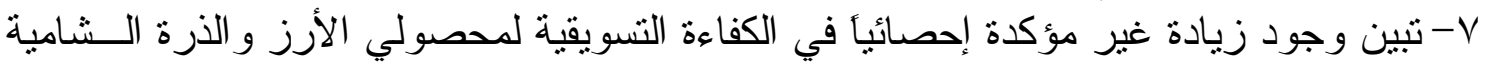

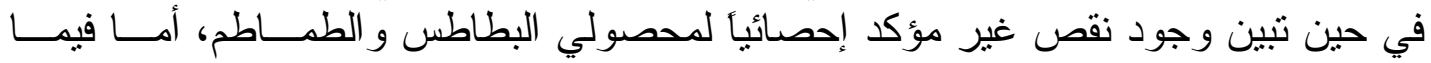

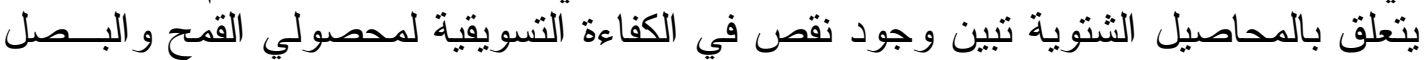

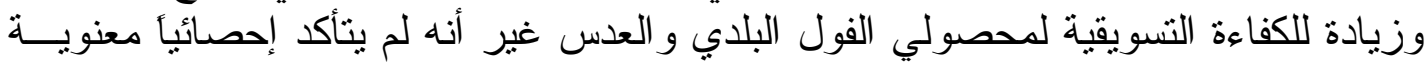
تلك الزيادة و النقص. ادة. 
Economic and Marketing Efficiency of Most Important Food Crops in Egypt

\author{
M.A. Abo-Nahoul; T. H. Ismail; G.A. El-Sogheir and Maha A. Sayed \\ Department of Agricultural Economics, Faculty of Agricultural, Assiut University
}

\title{
Summary and Results
}

This study aims mainly at identifying and determining the economic efficiency of eight food crops during the period 1987-2000. These crops are Wheat, Rice, Maize, Local Beans, Lentil, Onion, Potato, and Tomato. On the other hand, the study sheds lights on the marketing margins as well as marketing efficiency so that judging performance efficiency of production marketing activity of investigated crops. The Essential data used in the study were published and un- published data collected from Central Agency for Public Mobilization and Statistics (CAPMAS), Ministry of Agriculture and soil Reclamation. The methodology adopted in the study was condensed in some qualitative and quantitative economic analytic methods.

Many important outcomes resulted from the present study as follows;

1- There are statistically significant differences between the annual and monthly net annual yield and the annual and monthly annual return on each of the summer and winter crops studied.

2- There is a statistically significant increase in the average cost of unit production for summer and winter crops during the study period.

3- There is a statistically significant increase in both farm prices, wholesale prices and retail prices for the summer and winter crops studied.

4- There was a statistically significant increase in the marketing margins of both summer and winter crops, except for lentils from winter crops where the significance of the increase is statistically significant. 